\title{
Market Liquidity and Trader Welfare in Multiple Dealer Markets Evidence from Dual Trading Restrictions
}

\author{
Peter R. Locke \\ Commodity Futures Trading Commission \\ 2033 K Street, N.W. \\ Washington, DC 20581 \\ 202-418-5287 \\ Fax: 202-418-5527 \\ E-mail: PLOCKE@CFTC.GOV \\ Asani Sarkar \\ Federal Reserve Bank of New York \\ Research Department \\ 33 Liberty Street \\ New York, NY 10045 \\ 212-720-8943 \\ Fax: 212-720-1773 \\ E-mail: ASANI.SARKAR@NY.FRB.ORG \\ Lifan $\mathrm{Wu}$ \\ California State University, Los Angeles \\ Department of Finance and Law \\ 5151 State University Drive \\ Los Angeles, CA 90032 \\ 213-343-2870 \\ Fax. 213-343-6461
}

This version: July, 1998

Sarkar and $\mathrm{Wu}$ are grateful to the Office for Futures and Options Research of the University of Illinois at Urbana-Champaign for financial support, and to the Commodity Futures Trading Commission and the Chicago Mercantile Exchange for the provision of data. We also thank the referee, the editor, Paul H. Malatesta, and seminar participants at the Federal Reserve Banks of Atlanta and New York for comments. The views stated here are those of the authors and do not necessarily reflect the views of the Federal Reserve Bank of New York, the Federal Reserve System or the Commodity Futures Trading Commission or their respective staffs. All errors and omissions are our responsibility alone. 


\section{Market Liquidity and Trader Welfare in Multiple Dealer Markets \\ ABSTRACT}

\section{Peter R. Locke \\ Asani Sarkar \\ Lifan Wu}

JEL Classification number: G12, G13, G18

In the context of dual trading restrictions, we examine whether aggregate liquidity measures are appropriate indicators of trader welfare in multiple dealer markets. Consistent with our theoretical results, we show empirically that dual trading restrictions did not affect market liquidity significantly, but dual traders of above-average skills may have quit brokerage and switched to trading exclusively for their own accounts following restrictions. Further, customers of these dual-traders had lower trading costs in the period before restrictions relative to the trading costs of all customers after restrictions. 


\section{Market Liquidity and Trader Welfare in Multiple Dealer Markets}

\section{Introduction and Background}

The market microstructure literature has, at least since Demsetz (1968), focused primarily on the bid-ask spread as a measure of transactions costs and market efficiency. It has long been recognized, however, that the quoted bid-ask spread is inadequate for measuring market liquidity. According to Stoll (1985) and Grossman and Miller (1988), for example, the bid-ask spread measures liquidity precisely only when the market maker simultaneously crosses a trade at the bid and the ask. Hasbrouck (1993) discusses the shortcomings of traditional measures of transactions costs (such as the bid-ask spread) and proposes new, improved measures of liquidity.

In spite of criticisms, the bid-ask spread continues to be widely used for comparative market analysis and regulatory studies, as Hasbrouck (1993) points out. For example, an important regulatory issue of recent times is dual trading, a practice whereby floor traders on a futures exchange execute trades for their proprietary accounts and customers on the same day. ${ }^{1}$ The extensive literature evaluating the market liquidity impact of restrictions on dual trading focuses mainly on the bid-ask spread. The empirical evidence, however, remains confusing. Depending on the market studied, the correlation between dual trading and the bid-ask spread may be negative, positive or zero. $^{2}$

In this paper, we provide---in the context of dual trading regulation---additional theoretical and empirical evidence that aggregate liquidity measures (such as the average bid-ask spread) may be misleading indicators of traders' welfare in multiple dealer markets. In particular, we argue that, if dealers are heterogeneous with respect to trading skills, then the average bid-ask spread measures customers' cost of trading with a dealer of average skill. Therefore, a regulation may have little effect 
on the average bid-ask spread, but still hurt highly skilled dealers and their customers.

Our theoretical model analyzes the consequences of "dealer heterogeneity". In the model, based on Spiegel and Subrahmanyam (1992), hedgers and informed customers execute their orders through futures floor traders (dual traders and pure brokers). Risk-neutral informed customers trade based on signals about the asset value. Risk-averse hedgers trade to protect the values of their endowments of the risky asset. We assume that floor traders are of different skill levels and, further, that a more skilled floor trader attracts more hedgers to trade. Also in the spirit of Grossman (1989), the average skill of dual traders is assumed to be higher than that of pure brokers.

One result of the model is that customers' welfare and dual traders' personal trading revenues are increasing in the skill level, implying that a restriction on dual trading is welfare-reducing for customers of dual traders with above-average skill levels. Yet, provided the difference in average skill levels between dual traders and pure brokers is not too large, market depth (the inverse of the price impact from a trade) is relatively unaffected. These results are consistent with Fishman and Longstaff (1992), who, in the context of front running, argue that "customers' preferences regarding a market's trading rules cannot always be measured by the resulting bid-ask spread."

Our empirical analysis uses futures markets data to examine two episodes of dual trading restrictions: the Chicago Mercantile Exchange's (CME) top-step rule, which has effectively restricted dual trading in the S\&P index futures since June 1987; and CME rule 552, which has restricted dual trading in high volume contracts since May 1990. To study the effects of rule 552, we examine the Japanese Yen futures contract. ${ }^{3}$ Our results show that neither market depth nor the average realized bid-ask spread changed significantly following each of these restrictions.

Next, we investigate whether dual traders were heterogenous with respect to their skill levels and 
whether the restrictions had a differential impact on different dual traders. We find that dual traders were heterogenous with respect to their pre-restriction trading patterns. For example, the group of dual traders who chose to become pure brokers following restrictions was primarily engaged in trading for customers prior to restrictions.

Most importantly, we find that those dual traders who, following restrictions, became locals (i.e., traded exclusively for their own accounts), had significantly higher average personal trading volume and personal trading revenues prior to restrictions, as compared to those dual traders who continued to broker for customers following restrictions. Further, these differences occur on days when dual traders traded exclusively for their own account, and thus cannot be attributed to their customers' information. Since our theoretical model implies a correlation between dual traders' skill levels and their personal trading quantity and revenues, these results are consistent with the idea that highly skilled dual traders traded exclusively for their own accounts in the post-restriction period. In addition, customers of these skilled dual traders had lower trading costs before restrictions, relative to all customers after restrictions. Thus, dual trading restrictions may harm customers by reducing the quality of brokers who do customer business, as conjectured by Grossman (1989).

For regulatory policy, our analysis identifies areas of concern, although the overall economic impact of dual trading restrictions remains difficult to quantify. The effect of restrictions on average liquidity in these markets appears to be neutral, with potentially negative effects for some customers and traders. Broad-based measures of liquidity (such as the bid-ask spread), used in previous studies, are unable to capture the distributional effects of regulation---a subject of increasing interest by legislators. Our research, of course, makes no attempt to evaluate concerns about the frequency or severity of trading abuses underlying most dual trading restrictions. ${ }^{4}$ 
Regarding dealer heterogeneity, Cohen, Maier, Schwartz and Whitcomb (1986) comment on the complexity of the price formation process due to the "dynamic interaction of a large and diverse group" of trading agents. Kleidon and Willig (1995) discuss how diversity among Nasdaq market makers may make it difficult for market makers to collude. Cao, Choe and Hatheway (1997) and Corwin (1996) document significant heterogeneity among New York Stock Exchange (NYSE) specialist firms. Leuthold, Garcia and Lu (1994) find that some large traders in the frozen pork bellies futures market have significant price forecasting abilities. Board, Vila and Sutcliffe (1997) note substantial differences in quoting and trading behavior of market makers on the London Stock Exchange. To our knowledge, however, this paper is the first to analyze the link between dealer heterogeneity, market liquidity and the consequent implications for regulatory policy.

Our results are related to those of Bacidore (1997) and Ahn, Cao, and Choe $(1996,1997)$ who find that decimalization reduces quoted spreads but has no effect on trading volume. On the Nasdaq markets, apparently inferior execution (as measured by the bid-ask spread) by Nasdaq dealers has not deterred new firms from listing there or existing firms from continuing to remain on the exchange, as pointed out by Christie and Schultz (1994) and Lee (1993). In contrast, we find restrictions affect skilled dual traders but not realized spreads or market depth. The results of all these papers are, however, consistent with the idea that aggregate liquidity is only one dimension of market quality.

The theoretical literature refers to heterogenous trading motives of dual traders. Grossman (1989) asserts that dual traders are superior at order execution and market making. Also, dual traders provide flexibility by reacting quickly to changing market conditions, and, by competing with both pure brokers and market makers (at least in the short run), they enhance market liquidity. Fishman and Longstaff (1992), on the other hand, model dual traders as mimicking the trading decisions of 
informationally-motivated traders and reducing their trading profits. Roell (1990) and Sarkar (1995)

show that dual traders may also hurt uninformed traders and, as a consequence, liquidity may decrease. $^{5}$

As mentioned earlier, the empirical evidence on the effect of dual trading on liquidity is mixed and confusing. The Commodity Futures Trading Commission (CFTC) (1989) concludes that, while dual traders appear to supply liquidity with their personal trades, their personal trading is no more important than that of locals. Chang and Locke (1996) find that, in the high volume markets they examine, a restriction on dual trading has a positive effect on liquidity. But Smith and Whaley (1994) and Walsh and Dinehart (1991) offer evidence that dual trading may enhance liquidity.

The rest of the paper is organized as follows. Section II provides a theoretical analysis of dual trading and market liquidity when futures floor traders have different skill levels. In section III, we empirically estimate the effect of dual trading restrictions on the bid-ask spread. Section IV documents the occupational choice of dual traders following restrictions and estimates trading patterns and relative trading skills of dual traders prior to restrictions. In section $\mathrm{V}$, we estimate trading costs of customers of different dual trader groups, both before and after restrictions. Section VI concludes.

\section{The Futures Trading Model}

There is a single futures contract with random value $v$, where $v$ is distributed normally with mean 0 and variance $\Sigma_{v}$. Futures customers include $n$ informed traders, each of whom receives a signal about the true asset value and submits market orders. For an informed trader $i, i=1, \ldots, n$, the signal is $s_{i}=v+e_{i}$, where $e_{i}$ is drawn from a normal distribution with mean 0 and variance $\Sigma_{e}$. There are also many risk-averse uninformed traders ("hedgers"). As in Spiegel and Subrahmanyam (1992), each 
hedger $j$ has random endowment $w_{j}$ units of the futures contract. The endowment $y$ is normally distributed with mean 0 and variance $\Sigma_{w}$, and is independent of $v$. Hedgers have negative exponential utility functions with risk-aversion parameter $R$. As in Kyle (1985), the asset is priced by a market maker who makes zero expected profits conditional on the net order flow realized.

Customers submit orders to floor brokers for execution. There are potentially many floor traders in the futures pit, with varying skill levels. For our analysis, it is not important what precise skill a floor trader is endowed with (although, in the next section, we provide an example of a skill). We do require that such skills exist, that they differ across traders, and, most important, that a higher skilled floor trader attracts more hedgers to trade the futures contract.

Assumption 1. Higher skilled floor traders attract more hedgers to trade with them.

Why don't higher skilled floor traders attract more informed traders? It can be shown (proof available upon request) that dual traders' expected profits are decreasing in the number of informed traders $n$ when $n$ is large enough. The reason is that an increase in the number of informed traders decreases the value to dual traders of mimicking informed trades.

In our analysis, we do not distinguish between individual floor traders, but rather between two broad categories: dual traders and pure brokers. Pure brokers accept customer orders for execution. Dual traders may, in addition to brokerage, trade for their own accounts. We assume that the average skill level of dual traders is equal to or higher than that of pure brokers. ${ }^{6}$ Thus, from assumption one, more hedgers trade with dual traders than with pure brokers on average.

Assumption 2. The average skill level of dual traders is at least as high as that of pure brokers.

In the following section, we discuss these two assumptions in detail. We provide an example of a specific skill, and illustrate the relationship between skill levels and the number of customers 
(assumption one) and between skill levels of dual traders and pure brokers (assumption two).

\section{A. Heterogeneously Skilled Futures Floor Traders: A Discussion}

We discuss our assumptions with the help of an example of a skill---the ability to search for the "true" price $P$ of the asset (i.e., the liquidation value of the asset). At any time, several prices (bids and offers) are advertised in the pit. Assume that floor traders observe these prices with error. The error may occur because, for example, a trader is uncertain as to whether a particular price represents a trade at a bid or an offer. A more skilled trader distinguishes between bid and ask prices with greater accuracy to obtain a better estimate of the true price $P$.

To illustrate, suppose the pit is fragmented into several isolated sub-markets $i, i=1, \ldots, L$ each with its own, distinct sub-market price $p_{i}$. Suppose floor trader $j$ observes a signal $s_{i j}=p_{i}+u_{i j}$, where $u_{i j}$ is floor trader $j$ 's error in observing $p_{i}$. Let $u_{\mathrm{ij}}$ be normally distributed with mean zero and variance $\Sigma_{\mathrm{j}}$. Similarly, floor trader $k$ observes $s_{i k}=p_{i}+u_{i k}$, where $u_{i k}$ is distributed normally with mean zero and variance $\Sigma_{\mathrm{k}}$. If $\Sigma_{\mathrm{j}}<\Sigma_{\mathrm{k}}$, we say floor trader $j$ is more skilled than floor trader $k$.

Sub-market prices $p_{i}, i=1, \ldots, L$ are noisy indicators of the true price $P$. Thus, by searching submarkets $i=1, \ldots, n, n \leq L$, floor trader $j$ receives signals $s_{1 j}, . ., s_{n j}$ to form an estimate of the true price $\mathrm{E}\left(P \mid s_{l j}, . ., s_{n j}\right)=a_{j} S_{j}$, where $S_{j}=\sum_{i} s_{i j}, a_{j}=\operatorname{cov}\left(P, s_{i j}\right) / \operatorname{var}\left(S_{j}\right)$. The forecast error of floor trader $j$ is $\mid P$ $\mathrm{E}\left(P \mid s_{l j}, . ., s_{n j}\right) \mid$. Suppose floor traders $j$ and $k$ search the same number of sub-markets $m$. If floor trader $j$ is more skilled than floor trader $k\left(\Sigma_{\mathrm{j}}<\Sigma_{\mathrm{k}}\right)$, she has a lower forecast error. This attracts more hedgers to trade with floor trader $j$, increasing her commission income, which, in turn, provides her the resources to "search" more sub-markets subsequently (assuming search is costly). Over time, floor trader $j$ establishes a larger customer base and a reputation for superior skills. 
To illustrate assumption two, suppose floor traders incur a cost $w>0$ when searching for prices. Floor trader $j$ 's objective is to select $n$, the number of sub-markets to search, that minimizes her search cost function (for example, a candidate search cost function may be [(forecast error) $\left.\left.)^{2}+w n^{2}\right]\right)$. A pure broker searches till her expected marginal commission income equals her marginal search costs. A dual trader, in addition to commission income, also earns trading revenues and so, on average, a dual trader searches more prices, and is more likely to become skilled. ${ }^{7}$

\section{B. The Dual Trading Model}

Let $\alpha_{i}$ be an index of hedger participation with floor trader $i$. Formally, floor trader $i$ attracts $\alpha_{i} h$ hedgers to participate in trading, where $h \geq 1$ and $\alpha_{i} \geq 1$. From assumption one, if floor trader $i$ is more skilled than floor trader $j$, then $\alpha_{i}>\alpha_{j}$. Since there is a correspondence between skill levels and the hedger participation indices, we henceforth refer to $\alpha_{i}$ as the skill level of floor trader $i$.

Let $\alpha_{b}$ represent the average skill level of pure brokers and let $\alpha_{d}$ represent the average skill level of dual traders. From assumption two, $\alpha_{d} \geq \alpha_{b}$. We normalize so that pure brokers as a group have an average skill level $\alpha_{b}=1$ and dual traders as a group have an average skill level $\alpha_{d} \geq 1$. From now on, we write $\alpha \geq 1$ (without the subscript) to refer to the average skill level of dual traders only. Our results are qualitatively unchanged if we allow $\alpha_{b}$ to vary, so long as we interpret $\alpha=\alpha_{d} / \alpha_{b} \geq 1$ as the dual trader's relative skill level. A formal proof of this assertion is available upon request.

In the empirical analysis, we will be concerned with dual traders and pure brokers as groups, rather than as individuals. Thus, when solving the model, we assume there is a single dual trader (group) with skill level $\alpha \geq 1$, and $\alpha h$ hedgers and $n$ informed traders as customers. Similarly, we assume a single pure broker (group) with skill level one and $h$ hedgers and $n$ informed traders as 
customers. $\alpha$ and $h$ are common knowledge. Initially, we consider only equilibria where hedgers and informed customers choose either the dual trader or the pure broker. In section E, we analyze the case where the dual trader and the pure broker coexist.

In this section, we compute the equilibrium when hedgers and informed customers choose the dual trader. Informed trader $i, i=1, . ., n$ chooses $x_{i, d}$ to maximize conditional expected profits $\mathrm{E}[(v$ $\left.\left.p_{d}\right) x_{i, d} \mid s_{i}\right]$, where the price is $p_{d}=\lambda_{d} y_{d}$, the net order flow is $y_{d}=x_{d}+u_{d}+z$, the aggregate informed trade is $x_{d}=\Sigma_{i} x_{i, d}, u_{d}$ is aggregate hedgers' order flow and $z$ is the dual trader's order flow. Hedger $j, j=1, \ldots, \alpha h$ submits market order $u_{j, d} \quad u_{j, d}$ is chosen to maximize, conditional on endowment $y$, hedger $j$ 's certainty equivalent profits $G_{j, d}=\mathrm{E}\left(H_{j, d} \mid w_{j}\right)-(R / 2) \operatorname{var}\left(H_{, d} \mid \psi\right)$, where $H_{j, d}$ is hedger $j$ 's profits. Hedgers' total order flow is $u_{d}=\Sigma_{j} u_{j, d}$. We assume that hedger $j$ follows a linear trading strategy $u_{j, d}=D_{d} w_{j} .\left|D_{d}\right|$ denotes the absolute hedging intensity with the dual trader.

The dual trader chooses her personal trading quantity $z$ after observing the $n$-vector of informed trades $\left\{x_{1, d}, . ., x_{n, d}\right\}$ and the $\alpha h$ vector of hedger trades $\left\{u_{1, d}, . ., u_{\alpha h, d}\right\}$. Thus, the dual trader chooses $z$ to maximize conditional expected profits $\mathrm{E}\left[\left(v-p_{d}\right) z \mid\left\{x_{1, d}, \ldots, x_{n, d}, u_{1, d}, . ., u_{\alpha h, d}\right\}\right]$. Finally, she submits the net order flow $y_{d}$ to the market maker for execution. Given that the market maker makes zero profits, the price is $p_{d}=\mathrm{E}\left(v \mid y_{d}\right)$.

Define $t=\Sigma_{v} / \Sigma_{s}$, where $t$ is the unconditional precision of an information signal. Note that $0 \leq t \leq 1$. Further, define $Q=1+t(n-1)$, where $(Q-1) s_{i}$ represents informed trader $i$ 's conjecture (conditional on $s_{i}$ ) of the remaining $(n-1)$ informed traders' signals. For example, if $t=1$ (perfect information), informed signals are perfectly correlated, $Q=n$, and informed trader $i$ conjectures that other informed traders know $(n-1) s_{i}$--i.e., the informed trader believes other informed traders have the same information as she. Lemma 1 describes the solution to the trading model when hedgers and 
informed customers choose the dual trader.

Lemma 1: Suppose informed customers and hedgers choose the dual trader. An equilibrium exists if $n>1, t>0$ and $N_{1}>N_{2} / \sqrt{ } \alpha$, where $N_{1}$ and $N_{2}$ are defined in (5) and (6) below. Informed customer $i$ trades $x_{i, d}=A_{d} s_{i}$, the dual trader trades $z=B x_{d}-(0.5) u_{d}$, hedger $j$ trades $u_{j, d}=D_{d} w_{j}, j=1, \ldots, \alpha h$, where $D_{d}<0$, the market price is $p_{d}=\lambda_{d} y_{d}$ and:

$$
A_{d}=\frac{(Q-1)}{2 Q}\left(-D_{d}\right) \sqrt{\frac{\alpha t h \Sigma_{w}}{n \Sigma_{v}}}
$$

$$
B=\frac{1}{Q-1}
$$

$$
-\lambda_{d} D_{d}=\frac{2}{1+Q} \sqrt{\frac{n t \Sigma_{v}}{\alpha h \Sigma_{w}}}
$$

$$
D_{d}=\frac{\frac{N_{2}}{\sqrt{\alpha}}-N_{1}}{N_{1}-\frac{N_{3}}{\alpha}} \text {, where }
$$

$$
N_{1}=R \Sigma_{v}(2-t)
$$

$$
N_{2}=2 \sqrt{\frac{n t \Sigma_{v}}{h \Sigma_{w}}}
$$

$$
N_{3}=\frac{n t R \Sigma_{v}}{h(1+Q)}
$$

As in Spiegel and Subrahmanyam (1992), for $\lambda_{d}>0, D_{d}<0$ in equilibrium. Since $N_{1}>N_{3} \geq N_{3} / \alpha$ from definition, we need $N_{1}>N_{2} / N \alpha$, which requires that the number of informed traders $n$ is small 
while $\alpha, R, h, \Sigma_{w}$ and $\Sigma_{e}$ are all large. Intuitively, the amount of noise and risk-aversion must be large relative to information for the market maker to price the asset.

From (2), $n>1$ implies $B>0$ : the dual trader piggybacks on the informed order. From (1), piggybacking reduces informed trades (relative to the no-dual-trading benchmark) by the factor ( $Q$ 1) $/ Q$. Also, from the equilibrium $z$, the dual trader offsets half of hedgers' order flow.

\section{The Solution When a Pure Broker is Chosen}

Now, we compute the equilibrium assuming that hedgers and informed customers choose the pure broker. Informed trader $i, i=1, . ., n$ chooses $x_{i, b}$ to maximize conditional expected profits $\mathrm{E}[(v$ $\left.\left.p_{b}\right) x_{i, b} \mid s_{i}\right]$, where the price is $p_{b}=\lambda_{b} y_{b}$, the net order flow is $y_{b}=x_{b}+u_{b}$, the aggregate informed trade is $x_{b}=\Sigma_{i} x_{i, b}$, and $u_{b}$ is aggregate hedgers' order flow. Hedger $j, j=1, \ldots, h$ submits market order $u_{j, b}$ to the pure broker. $u_{j, b}$ is chosen to maximize (conditional on endowment) the certainty equivalent profits of hedger $j, j=1, . ., h$, defined as $G_{j, b}=\mathrm{E}\left(H_{j, b} \mid w_{j}\right)-(R / 2) \operatorname{var}\left(H_{j, b} \mid w_{j}\right)$, where $H_{j, b}$ is hedger $j$ 's profits with the pure broker. Denote hedgers' total trading volume with the pure broker as $u_{b}=\Sigma_{j} u_{j, b}$. We assume hedger $j$ follows a linear trading strategy $u_{j, b}=D_{b} w_{j} \cdot\left|D_{b}\right|$ denotes the absolute hedging intensity with the pure broker. The pure broker submits the net order flow $y_{b}$ to the market maker for execution. Thus, the price is $p_{b}=\mathrm{E}\left(v \mid y_{b}\right)$. Lemma 2 describes the solution when hedgers and informed customers choose the pure broker.

Lemma 2: Suppose hedgers and informed customers choose the pure broker. An equilibrium exists if $t>0$ and $N_{1}>N_{2}$, where $N_{i}, i=1,2,3$ are defined in (5)-(7). Informed customer $i$ trades $x_{i, b}=A_{b} s_{i}$, hedger $j$ trades $u_{j, b}=D_{b} w_{j}, j=1, \ldots, h$, where $D_{b}<0$, the price is $p_{b}=\lambda_{b} y_{b}$, and: 


$$
\begin{gathered}
A_{b}=\left(-D_{b}\right) \sqrt{\frac{t h \Sigma_{w}}{n \Sigma_{v}}} \\
-\lambda_{b} D_{b}=\frac{1}{1+Q} \sqrt{\frac{n t \Sigma_{v}}{h \Sigma_{w}}} \\
D_{b}=\frac{N_{2}-N_{1}}{N_{1}-N_{3}}
\end{gathered}
$$

\section{Floor Trader Heterogeneity, Customers' Welfare and Market Depth}

In this section, we relate trader heterogeneity to customers' welfare and market depth. Our first result shows that higher skill levels are "good" for customers and the market. Higher levels of $\alpha$ affect the hedging intensity in two opposite ways. An increase in the skill level reduces the price impact of hedger trades and enables the uninformed traders to hedge more. But it reduces the incentive to hedge by increasing the residual endowment risk (i.e., the uncertainty arising from not knowing the endowments of other hedgers) which, in turn, increases the variance of the price, conditional on the hedger's own endowment. Formally, the residual endowment variance is given by $(\alpha h-1) R \Sigma_{\mathrm{w}}\left(\lambda_{\mathrm{d}} D_{d}\right)^{2} / 4$. In contrast, the total endowment risk $\alpha h R \Sigma_{\mathrm{w}}\left(\lambda_{\mathrm{t}} D_{d}\right)^{2} / 4$ is independent of the number of hedgers because the increase in variance due to an increase in the number of hedgers $\alpha h$ is exactly offset by a reduction in the price impact $\left(\lambda_{\mathrm{d}} D_{d}\right)^{2}$.

An increase in $\alpha$ increases the hedging intensity if the marginal decrease in the price impact is greater than the marginal increase in the residual endowment risk. This is likely to occur if the price impact $\left(N_{2}\right)$ is initially relatively high and the relative endowment risk $\left(N_{3}\right)$ is initially relatively low. More precisely, Proposition 1 requires that $\left(N_{2}\right)^{2}>N_{1} N_{3}$, which is likely if $R, \Sigma_{w}$ and $\Sigma_{w}$ are not too 
large relative to the number of informed traders $n$ and the information precision $t^{8}$ This ensures that the hedging intensity, informed profits, and market depth increase with the skill level. A slightly stronger version of the same condition ensures that hedgers' utility is also increasing in the skill level. Proposition 1. Let $N_{2}-\left(N_{1} N_{3}\right)^{1 / 2}=k$. If $k>0$, then the hedging intensity, informed profits and the market depth are increasing in the skill level $\alpha$. If, in addition, $k$ is large (as defined in the appendix), then hedgers' utility is also increasing in $\alpha$.

Proposition 1 implies that policy makers should consider the effects of futures regulation on the average skill level of floor traders. Since skill levels are difficult to infer, the common method is to evaluate rules by estimating changes in the market bid-ask spread or depth. From (3) and (9), the difference in market depth between the dual trader and pure broker is:

$$
\frac{1}{\lambda_{d}}-\frac{1}{\lambda_{b}}=(1+Q) \sqrt{\frac{h \Sigma_{w}}{n t \Sigma_{v}}}\left(\frac{\sqrt{\alpha}\left|D_{d}\right|}{2}-\left|D_{b}\right|\right)
$$

In the next proposition, we compare market depth with and without dual trading.

Proposition 2. Suppose $\left(N_{2}\right)^{2}>N_{l} N_{3}$. There exists $\alpha^{\star}$ (defined in the appendix), $1<\alpha^{\star}<4$, such that if $\alpha$ is greater (less) than $\alpha^{\star}$, market depth increases (decreases) with a ban on dual trading. If $\alpha=\alpha^{\star}$, then market depth is unaffected by a ban on dual trading.

There are two effects of dual trading on market depth. Market depth is halved with the dual trader because she offsets half of hedgers' order flow. But higher hedger participation with the dual trader also increases depth by a factor $\sqrt{ } \alpha$. Hence, provided the hedging intensity is increasing in $\alpha$, depth increases with dual trading when $\alpha$ exceeds four. When $\alpha=1$, the hedging intensities are the same with the dual trader and the pure broker, and depth decreases with dual trading, reflecting the dual trader's reduction of the hedgers' net order flow. When $\alpha$ is between one and four, market depth 
may remain unchanged when dual trading is banned.

Proposition 2 rationalizes the conflicting empirical results found in studies of dual trading. A ban on dual trading may lead to an increase or decrease in market depth, depending on the relative skill levels of the dual trading population. In particular, if dual traders are highly skilled relative to pure brokers, market depth decreases when dual trading is banned. However, if the difference in skill levels between dual traders and pure brokers is not that great, a ban on dual trading may have no discernible effect on depth. Consistent with this idea, Chang and Locke (1996) find that a ban on dual trading did not affect liquidity, and argue that dual traders were marginal providers of liquidity prior to the ban.

Corollary one determines the magnitude of the critical skill level $\alpha^{\star}$ in a given market.

Corollary 1. $\alpha^{\star}$ is negatively related to the price impact of hedgers' trades.

In our model, hedgers' price impact with dual trading is given by $\lambda_{d}\left|D_{d}\right|$, or equivalently, by the variable $N_{2}$. The following examples show the relationship between $\alpha^{\star}$ and $N_{2}$. Example 1 (market where hedgers' price impact is high). Let $N_{2}=N_{1}-\epsilon$, where $\epsilon>0$ and arbitrarily small. Since, in equilibrium, $N_{2}<N_{l}$, $\left(N_{l}-\epsilon\right)$ is the highest allowable value of the price impact. Further, since $N_{1}>N_{3},\left(N_{2}\right)^{2}>N_{1} N_{3}$ is satisfied. We show in the appendix that $\alpha^{\star}=1+2$, where $>0$ and arbitrarily small. Thus, in markets where hedgers' price impact is high, even moderately skilled dual traders have a positive effect on liquidity.

Example 2 (market where hedgers' price impact is low). Let $\left(N_{2}\right)^{2}-N_{1} N_{3}=\in$ and $N_{3}=$, where $\in>0$, $>0$ and both $\in$ and are arbitrarily small. Thus, the price impact is at its lowest allowable limit, yet $\left(N_{2}\right)^{2}>N_{1} N_{3}$. We show in the appendix that $\alpha^{\star}=4-8$, where $>0$ and arbitrarily small. Thus, in markets where hedgers' price impact is low, dual traders must be highly skilled to have a positive 
impact on liquidity.

Proposition 3. If $\left(N_{2}\right)^{2}>N_{3}$, then dual trader's expected trading volume and revenues are increasing in $\alpha$.

Thus, restrictions are likely to hurt dual traders of above average skills more, since their opportunity cost of not dual trading is also higher than average. As a result, customers of skilled dual traders are worse off from the restrictions (by proposition one). If many highly skilled dual traders quit trading the affected contract, the average skill level of the remaining dual traders goes down, and depth decreases. However, if there are few high-skilled dual traders, market depth may not decrease discernibly, yet some customers are adversely affected.

We can formalize the idea "market depth does not decrease discernibly" as follows. ${ }^{9}$ Suppose $\alpha$ is close to, but not equal to, $\alpha^{\star}$. If a ban on dual trading leads to a large change in market depth, then the effect is "discernible". We can show (proof available upon request) that, for reasonable values of the asset volatility $\Sigma_{v}$, the market depth function is not very elastic with respect to $\alpha$, when $\alpha$ is close to $\alpha^{\star}$. Specifically, let $M$ be the difference in market depths (i.e., the right-hand-side of (11)), and suppose we perturb any one of the parameters $N_{i}, i=1,2,3$, by an arbitrarily small amount . Let $M$ be the resulting change in $M$. Then, for reasonable values of $\Sigma_{v}, M / M<1$.

Corollary 2. If $\left(N_{2}\right)^{2}>N_{1} N_{3}$, then a ban on dual trading hurts dual traders of above average skills and their customers. However, there may be little effect on market depth.

\section{E. Coexistence of Pure Brokers and Dual Traders}

In this section, we extend the dual trading model by allowing pure brokers and dual traders to coexist prior to the dual trading ban. For the sake of brevity, proofs are not reported, but are 
available from the authors upon request.

There are two brokers in the market, a dual trader and a pure broker. Assume that $n_{1}$ informed traders execute orders through the dual trader, and $n_{2}$ informed traders execute orders through the pure broker, with $n_{1}+n_{2}=n$. For simplicity, we assume uninformed traders are noise traders, as in Kyle (1985). A proportion $\alpha_{d}$ of noise trades $u$ go though the dual trader, while a proportion $\alpha_{b}$ of noise trades $u$ go through pure brokers, with $\alpha_{d} \geq \alpha_{b}{ }^{10}$

Informed trader $i, i=1, \ldots, n_{1}$ submits $x_{i, d}$ to the dual trader, whereas informed trader $j, j=1, \ldots, n_{2}$ submits $x_{j, b}$ to the pure broker. The dual trader observes the orders of $n_{1}$ informed traders and noise trades of size $\alpha_{d} u$, and trades $z\left(x_{l}, \alpha_{d} u\right)$, where $x_{1}=\Sigma_{i} x_{i, d}$. The price is $p=\lambda y$, the net order flow is $y$ $=x_{1}+x_{2}+z+\alpha_{d} u+\alpha_{b} u, x_{2}=\Sigma_{j} x_{j, b}$ is the aggregate informed trade with the pure broker, and the size of noise trades with the pure broker is $\alpha_{b} u$. Informed trader $i, i=1, . ., n_{1}$, maximizes conditional expected profits $\mathrm{E}\left[(v-p) x_{i, d} \mid s_{i}\right]$, given the dual trader's optimal trading rule $z\left(x_{1}, \alpha_{d} u\right)$ and the trades of informed traders executing through the pure broker. Similarly, informed trader $j, j=1, . ., n_{2}$ maximizes profits $\mathrm{E}\left[(v-p) x_{j, b} \mid s_{j}\right]$, given the trades of the other agents.

The basic difference in solution method with the previous models is that, given $z\left(x_{l}, \alpha_{d} u\right)$, the trading intensities $A_{d}$ and $A_{b}$ of informed traders executing through the dual trader and the pure broker, respectively, must be solved simultaneously. When $n_{1}=0$, the model collapses to the pure broker solution in lemma two. When $n_{2}=0$, the model collapses to the dual trader solution in lemma one.

For $n_{1}>0$ and $n_{2}>0$, we can show existence of equilibrium, but comparative static exercises are difficult due to the complexity of the expressions. However, numerical examples suggest that the qualitative results obtained earlier do not change. For example, suppose $t=0.1, \alpha_{b}=1, n_{1}=10$ and $n_{2}=1$. 
Then, in the extended model, the (inverse of) market depth $\lambda=1.06 \sqrt{\Sigma_{u}} /\left[\left(\alpha_{d}+2\right) \sqrt{ } \Sigma_{v}\right]$. Now, suppose there is a ban on dual trading, and the ten informed traders executing through the dual trader all switch to the pure broker. Then $n_{1}=0, n_{2}=11$ and (the inverse of) market depth is $\lambda_{b}$, where $\lambda_{b}$ is given by (9), after substituting $\Sigma_{u}=\left(-D_{b}\right) h \Sigma_{w}$ to adjust for the fact that uninformed traders are noise traders, instead of hedgers. It can be shown that, if $\alpha_{d}=1.02,(1 / \lambda)=\left(1 / \lambda_{b}\right)$---i.e., market depth remains unchanged when dual trading is banned.

We have established the possibility that, as a consequence of regulation, an unchanged level of average liquidity may coexist with a decrease in some traders' welfare. The remainder of this paper analyzes empirically whether such a scenario holds for two specific episodes of dual trading restrictions.

III. An Empirical Analysis of Market Liquidity and Dual Trading Regulation

In this section, we consider the impact of dual trading restrictions on market liquidity. In section IV we analyze dual trader heterogeneity. Our null hypothesis is:

Hypothesis 1. Dual trading restrictions have no effect on market liquidity.

After describing our data, we look at some preliminary statistics to infer whether markets were sufficiently active for customers to benefit from higher skill levels (section B); and to infer the skill level of dual traders relative to that of pure brokers (section C). Finally, in section D, we directly estimate the change in liquidity after restrictions.

\section{A. Data and Sample Descriptions}

The Computerized Trade Reconstruction (CTR) data is used for two futures contracts which 
trade on the CME, the S\&P 500 index and the Japanese Yen. The data consist of detailed records for every transaction on the floor of the exchange. For each transaction, the record contains the trade type, the broker's identification number, the number of contracts traded, the buy-sell indicator and the price. The record also indicates four different customer types for a floor trader's transaction. ${ }^{11}$ For identifying dual trading, only two types--trades executed for the trader's own account and for outside customers--are relevant, and only these transactions are included in the sample.

To categorize floor traders, we calculate a trading ratio for each floor trader for each day she is active. Specifically, define $d$ as the proportion that personal trading volume is of a floor trader's total trading volume on a day. For each floor trader, a trading day is a local day if $d>0.98$, a broker day if $d<0.02$ and a dual day if $d$ lies on the closed interval [0.02,0.98]. ${ }^{12}$ A floor trader with at least one dual day in the sample is defined as a dual trader. A floor trader with only local (broker) days in the sample is defined as a local (pure broker).

We use a three-month window to examine the effect of the CME's rules. The sample period covers May 1 through July 31, 1987 for the S\&P 500 index futures contract with the top-step rule effective from June 22. For the Yen, the sample period covers April 1 through June 28, 1991, with the rule banning dual trading effective from May 20. The pre and post-rule samples are defined according to the event date on which the rule was imposed. For both contracts, there are 35 days in the pre-rule sample and 29 days in the post-rule sample. ${ }^{13}$ Floor traders are categorized as dual traders, pure brokers or locals in each of the two samples separately.

\section{B. Trading Activity in Futures Markets}

For higher skill levels to benefit customers and market liquidity, proposition one requires that 
the market is "sufficiently" active. Among other things, this means that $h$, the number of hedgers, is large (see footnote 8 ). We proxy $h$ by the average number of daily trades for customers and the average daily customer trading volume.

Table 1 shows summary statistics on the typical daily trading of a floor trader before and after restrictions. We combine the local days, broker days, and dual trading days of all traders. For the S\&P 500 futures, activity on dual trading days is lower after the top step rule. Activity on other types of trader days actually increased, however, so that average daily customer trades and trading volume show little change overall. For the Yen futures, however, activity falls on both dual and non-dual trading days, so that average daily customer trades and trading volume are lower after restrictions.

In absolute terms, the level of activity is high compared to other futures contracts both before and after restrictions. For example, the daily means of customer trades and trading volumes are higher than the numbers reported by Locke and Sarkar (1996) for the Treasury Bills, Soybean Oil and Live Hog futures in 1990-91. Further, dual trading was banned in the Yen futures from 1991 because the CME deemed it was a high-volume contract. The relatively high volume levels of the S\&P 500 futures is common knowledge. Thus, markets in our sample appear to have been sufficiently active for higher skill levels of dual traders to benefit customers.

\section{The Relative Importance of Dual Trading}

As an indication of $\alpha$, the skill level of dual traders relative to that of pure brokers, we study the relative importance of dual trading to the market. The justification comes from lemma A2 of the appendix, which shows that hedgers' trading volume is increasing in $\alpha$. The relevant statistics are shown in table 1. 


$$
S_{t}=a_{0}+a_{1} V_{t}+a_{2} V O L_{t}+a_{3} M_{t}+a_{4} D_{t}+e_{t}
$$

Statistics for the S\&P 500 are presented in the upper half of table 1. Prior to the top-step rule, dual trading days accounted for only about $23 \%$ of all trader days, but $45 \%$ of all trades, $47 \%$ of total trading volume and $72 \%$ of all customer volume. Following the top-step rule, only $8 \%$ of trader days, $12 \%$ of trades and less than $12 \%$ of trading volume occurred on dual trading days. The numbers for the S\&P 500 futures suggest that, relative to that of pure brokers, the average skill level of dual traders may have been high before restrictions, but possibly decreased following restrictions.

The lower half of table 1 shows statistics for the Japanese Yen. Relative to the S\&P 500, dual trading days were a smaller part of total market activity even prior to the ban. Dual trading days accounted for $15 \%$ of trader days, $23 \%$ of trades and $25 \%$ of trading volume. Following restrictions, dual trading days accounted for $6 \%$ or less of total trader days, number of trades or trading volume. These numbers suggest that average skill levels of dual traders in the Yen futures were, perhaps, no higher than that of pure brokers prior to restrictions.

\section{The Effect of Dual Trading Restrictions on Market Liquidity}

We proxy liquidity by two measures: the average realized bid-ask spread and the market depth. The average bid-ask spread is computed as the volume weighted average buy price minus the volume weighted average sale price for all customers (i.e., it is the negative of customer trading profits). We calculate the spread for each day for each floor trader and then aggregate across all customer trades. Separate calculations are made both before and after the dual trading restrictions. To estimate the effect of the restriction on liquidity, the following regression is estimated:

where, for day $t, S_{t}$ is the realized spread in dollars, $V_{t}$ is customer trading volume, $V O L_{t}$ is 
the standard deviation of buy prices for customer trades, $M_{t}$ is the number of floor traders trading for their own account, and $D_{t}=1$ in the pre-rule periods and 0 otherwise. This analysis parallels Smith and Whaley (1994) and Chang and Locke (1996).

Our results are presented in table 2. For neither contract is the coefficient $a_{4}$ significantly different from zero, indicating that the realized bid-ask spread was unaffected by restrictions, a result consistent with Chang and Locke (1996). The Durbin-Watson statistic $D=2.3$ for the S\&P 500 and $D=1.81$ for the Yen. Since the upper critical value of $D$ is 1.73 for both contracts, the null hypothesis of zero autocorrelation cannot be rejected at the five per cent level of significance.

We rerun (12) using the price impact of a trade (the inverse of market depth) as the dependent variable. The price impact is defined as in Kyle (1985)---i.e., the change in the price divided by the change in the net order flow. Empirically, the price impact is calculated as follows. For each trading bracket, we divide the price change (the difference between the prices of the first and last trades in the bracket) by the net customer trading volume in the bracket to obtain the price impact for that bracket. We then average across trading brackets in a day to get the daily price impact. The results, reported in table 3, are consistent with those in table 2. For neither contract is the coefficient $a_{4}$ significantly different from zero, indicating that the market depth was unaffected by restrictions.

\section{Trader Heterogeneity and Dual Trading Restrictions.}

In the above analysis, we failed to find evidence that dual trading restrictions affect liquidity. However, there was some indirect evidence suggesting that dual traders in the S\&P 500 possessed relatively high skills prior to restrictions. Further, after the top step rule, dual traders appear to have 
only average skill levels. In this section, we examine more rigorously whether the restrictions had a greater impact on dual traders of above-average skills.

Our procedure for establishing heterogeneity of dual traders is as follows. First, we record the occupational choice of dual traders following restrictions (e.g., whether a dual trader became a pure broker following restrictions). Next, the dual trader sample in the pre-restriction period is split into subsamples based on the observed occupational choice of these dual traders following restrictions. Finally, we test for systematic differences in dual traders' personal trading volume and revenues (both correlated with skill levels, by proposition three) across different groups of dual traders for the pre-restriction period. To control for information-based dual trading, the comparisons are made only for days in which dual traders traded exclusively for their own accounts.

\section{A. Occupational Choice of Dual Traders Following Restrictions}

In this section we follow dual traders in the respective markets, from their behavior in the prerestriction period to their choice of occupation in the post-restriction period. A dual trader has four possible reactions to the restrictions. First, they could continue to dual trade according to the CME's rules--i.e., if they are not on the top step of the S\&P 500, or if they switch from local to broker once a day in the Yen pit. Second, they could become locals. Third, they could become exclusive brokers. Fourth, they may exit the particular contract which is subject to the restriction.

Panel A of table 4 reports this transition matrix for all floor traders around the time restrictions were implemented. Of floor traders switching occupations but not quitting, the primary migration involves dual traders and brokers becoming locals. The percentage of floor traders who continue in their original occupations following restrictions are: for the S\&P 500, 25\% of pure 
brokers, $67 \%$ of locals and $61 \%$ of dual traders; for the Yen, $36 \%$ of pure brokers, $62 \%$ of locals and $58 \%$ of dual traders, respectively. Panel B shows that, for both contracts, the transition matrix for dual traders changes very little when we consider active floor traders (defined as those who traded on at least 2 days during the pre-rule sample period). We obtain similar results when we define active dual traders as those trading for at least three or four days.

Are floor traders' occupational choice due to dual trading restrictions, or for reasons unrelated to regulation? For an answer, note that the restrictions should have little effect on the occupational choice of locals and pure brokers. In panel A, instances of pure brokers and locals switching occupations are extremely few, although many discontinue trading. When we consider relatively active floor traders, however, higher proportions of locals and pure brokers remain in their original occupations than do dual traders. When we consider the population of floor traders who switched occupations, but did not quit trading, this difference in behavior of dual traders and others is even more striking. Thus, the evidence suggests that the restrictions played a key role in dual traders' occupational choice.

Our examination of the relevant CFTC data also indicates that dual traders who quit their home pit following restrictions did not migrate to a different pit in the exchange. This is consistent with Chang, Locke and Mann (1994), who examine exchange-wide trading in the currency and Eurodollar markets affected by Rule 552, and Kuserk and Locke (1993), who present evidence of the lack of migration of traders across various commodities within a day.

\section{B. Dual Traders' Relative Trading Pattern Before Restrictions}

Table 5 shows summary statistics for dual traders who changed occupations following 
restrictions. Dual-locals (dual-brokers) were dual traders in the pre-restriction period who switched to executing exclusively personal (customer) trades in the post-restriction period. Dual-quitters are those dual traders in the pre-restriction period who failed to trade in the affected contract in the postrestriction period.

For both contracts, dual-brokers were predominantly involved in trading for their customers on all their days in the pre-rule period. For example, in the S\&P 500, dual-brokers had only 24 local days out of 261 trader days. On their dual trading days, they traded only 116.25 contracts on average for their own accounts, but 588.68 contracts for customers. Similarly, for both contracts, dual-locals were almost entirely involved in trading for their own accounts on both their dual and non-dual days prior to the top-step rule.

The trading of dual-quitters show no consistent pattern. In the S\&P 500, they were primarily locals when they were not dual trading, but mostly traded for customers on their dual days. In the Yen pit, dual-quitters traded mainly for customers on both their dual and nondual trading days.

Table 6 shows the trading pattern for dual-duals (i.e., those floor traders who were dual traders both before and after restrictions). In contrast to the other dual trader groups, dual-duals have substantial trading activity on both local and broker days, although they tend to trade relatively more for customers than for their own accounts. This is particularly true for the pre-restriction period. These results establish the heterogeneity of dual traders with respect to their trading patterns.

Proposition three predicts that skill levels are correlated with dual traders' personal trading volume. We take the personal trading volume of dual-duals in the pre-restriction period as our benchmark, and compare it with the personal trading volumes of the remaining three dual trader groups for the pre-restriction period. Since higher personal trading by dual traders could be 
motivated by both private information and skill levels, we perform the comparison for the local days of dual traders only---days when they are less likely to know the customer order flow.

Hypothesis 2. During the pre-restriction period, the distribution of personal trading quantities of all four dual trader groups on their local days are the same.

Table 7 reports personal trading quantities of different groups of dual traders on their locals days prior to restrictions. The Wilcoxon $Z$ statistic is used to test the null hypothesis that the distribution of personal trading quantities for dual-duals is the same as the remaining dual trader groups (i.e., dual-brokers, dual-locals and dual-quitters). For both contracts, dual-locals had the highest mean and median daily personal trading volumes on their local trading days. The Wilcoxon $Z$ statistic indicates that the distribution of personal trading quantities for dual-locals was significantly different than that of dual-duals for both contracts. Further, dual-brokers had the lowest mean and median quantities among the four groups in all but one case, although the distribution of their quantities was not significantly different from that of dual-duals.

Since skills and personal trading quantities are correlated, we conclude that dual traders who continued to provide brokerage for customers following restrictions (i.e., dual-duals and dualbrokers) had lower trading skills than dual traders who quit brokerage following restrictions (i.e., dual-locals). We defer judgement on the dual-quitters, who had significantly lower quantities than dual-duals in the S\&P 500 pit.

\section{Dual Traders' Personal Trading Revenues Before Restrictions}

Proposition three further suggests that trading skills are correlated with dual traders' personal trading revenues. We use the dual-duals as the benchmark group and compare the distribution of 
their per contract revenues during the pre-restriction period with those of the other three dual trader groups (i.e., dual-brokers, dual-locals, and dual-quitters). As before, the comparisons are made only for local days of dual traders prior to dual trading restrictions.

Hypothesis 3. During the pre-restriction period, the distribution of personal trading revenues per contract of all four dual trader groups on their local days are the same.

Aggregate trading revenues for each dual trader are computed on a daily basis. For each trader, and for each day, the value of purchases is subtracted from the value of sales, with imbalances valued at the daily settlement price (marked-to-market). Daily revenues are then divided by the number of round-trip transactions for each floor trader, to obtain daily revenues per contract.

Table 8 reports personal trading revenues per contract of different groups of dual traders on their local days prior to dual trading restrictions. For the S\&P 500, dual-locals had the highest mean and median revenues per contract; their median revenues per contract were higher than that of dualduals by a cash equivalent value of $\$ 32.50$ per contract. Both dual-duals and dual-brokers had lower per contract mean and median revenues compared to the other two groups. The Wilcoxon $Z$ statistic indicates that the distribution of personal trading revenues per contract for dual-locals was significantly different than that of dual-duals.

For the Yen, dual-locals had higher median revenues per contract than all other groups except dual-brokers. However, differences in the distribution of revenues between different groups of dual traders were not significant. The results here support our earlier result on trading quantities. Dual traders who quit brokerage to trade for themselves had higher trading skills compared to those dual traders who continued to broker customer trades following the restrictions. The evidence is strong for the S\&P 500 and weak for the Yen futures. 
For the S\&P 500, dual-quitters had higher mean and median revenues than dual-duals, and the Wilcoxon test shows that the distribution of their revenues is significantly different from that of dual-duals. Recall that dual-quitters in the S\&P 500 had lower mean and median quantities than dual-duals. Thus, evidence on the skill level of dual-quitters in the S\&P 500 is inconclusive.

We combine the dual-duals and the dual-brokers into one group and repeat the analyses of tables 7 and 8 . This has three benefits. The number of observations for the combined group is 537 for the S\&P 500 and 91 for the Yen, whereas the number of observations for dual-brokers is very small (24 for the S\&P 500 and 2 for the Yen). Also, we remove a potential error from misclassifying some dual-brokers as dual-duals. ${ }^{14}$ Finally, we have a sharper comparison between the trading skills of dual traders who continued to broker and those who did not. The results (not reported but available upon request) are not qualitatively different from those of tables 7 and 8 .

Finally, we repeat the analysis of table 8 using aggregate personal trading revenues. The results do not change, except that dual-quitters no longer have significantly different daily revenues from the combined group. This is not surprising, since dual-quitters had lower mean and median quantities and higher mean and median revenues per contract compared to dual-duals.

\section{Dual Trading Restrictions and Customer Trading Costs Revisited}

In this section, we directly test our conjecture that some customers may have been hurt by dual trading restrictions, even though customers as a group were not. In particular, customers of dual traders who quit brokerage may have higher trading costs after restrictions, especially in the S\&P 500 futures. Thus, we combine dual-locals and dual-quitters into one group, called non-brokers. ${ }^{15} \mathrm{We}$ compute customer trading costs of the three dual trader groups---dual-duals, dual-brokers, and non- 
brokers---on their broker days before restrictions. We compare the distribution of these trading costs to the distribution of customer trading costs on the broker days of all brokers (i.e., dual traders and pure brokers) after restrictions. As before, customer trading costs for a group are the volume weighted average buy price minus the volume weighted average sale price for all customers in that group.

Table 9 reports the results. In the S\&P 500 futures, customers of all dual trader groups had higher mean and median trading costs on their broker days after restrictions, although the difference in the distribution of trading costs is significant only for customers of non-brokers (at a 7 per cent level of significance), and marginally significant for customers of dual-brokers (at a 10.42 per cent level of significance). This result supports Grossman's (1989) contention that, by speculating with their own capital, dual traders have a better "feel" for the market and, consequently, are able to get better "fills" for customers. The distribution of trading costs for customers of dual-duals do not change after restrictions, supporting our contention that these dual traders are of average skills. Customer trading costs of all groups remain unchanged in the Yen futures, consistent with earlier results suggesting that the skill differential between dual traders and pure brokers is not large in the Yen futures.

\section{Conclusion}

In the context of dual trading restrictions, we examine whether aggregate liquidity measures are appropriate indicators of trader welfare in markets with multiple, heterogeneously skilled dealers. Our theoretical results show that dual trading restrictions, while hurting skilled dual traders and their customers, may have little impact on market depth if average skill levels of dual traders and pure 
brokers are not too different. We find empirical evidence consistent with the above scenario. Although the average cost of liquidity in our sample did not change significantly after dual trading restrictions, dual traders of above-average trading skills switched to trading exclusively for their own accounts after restrictions. Further, their customers had lower trading costs before restrictions relative to customers in the post-restriction period.

Our results suggest that, in multiple dealer markets, broad based liquidity measures may be insufficient to capture the total welfare effects of microstructure regulation. Traditional liquidity measures may need to be supplemented by welfare indicators for specific groups of dealers and their customers (e.g., professional and retail customers). 


\section{REFERENCES}

Abramowitz, M. and C. A. Stegun (eds.). Handbook of Mathematical Functions With Formulas, Graphs, and Mathematical Tables. New York, Dover (1972).

Ahn, H.; C. Q. Cao; and H. Choe. "Decimalization and Competition Among Exchanges: Evidence From the Toronto Stock Exchange Cross-Listed Securities.” Journal of Financial Markets, forthcoming.

Ahn, H.; C. Q. Cao; and H. Choe. "Tick Size, Spread and Volume.” Journal of Financial Intermediation, 5 (1996), 2-22.

Bacidore, J. "The Impact of Decimalization on Market Quality: An Empirical Investigation of the Toronto Stock Exchange." Journal of Financial Intermediation, 6 (1997), 92-120.

Board, J.; A. F. Vila; and C. Sutcliffe. "Market Maker Heterogeneity. Evidence From the London Stock Exchange." Working Paper, the Bank of England (1997).

Cao, C.; H. Choe; and F. Hatheway. "Does the Specialist Matter? Differential Execution Costs and Intersecurity Subsidization on the NYSE." Journal of Finance, 52 (1997), 1615-1640.

Chakravarty, S. "Should Actively Traded Futures Contracts Come Under the Dual Trading Ban?" Journal of Futures Markets 14, 661-684.

Chang, E. C. and P. R. Locke. "The Performance and Market Impact of Dual Trading: CME Rule 552." Journal of Financial Intermediation, 5 (1996), 23-48.

Chang, E. C.; P. R. Locke; and S. C. Mann. "The Effect of CME Rule 552 on Dual Traders." Journal of Futures Markets, 14 (1994), 493-510.

Christie, W. G. and P. H. Schultz. "Why do Nasdaq Market Makers Avoid Odd-eighth Quotes?" Journal of Finance, 49 (1994), 1813-1840.

Cohen, K. J.; S. F. Maier; R. A. Schwartz; and D. K. Whitcomb. The Microstructure of Securities Markets. Prentice Hall, New Jersey (1986).

Commodity Futures Trading Commission. Economic Analysis of Dual Trading on Commodity Exchanges. Division of Economic Analysis, Washington, DC (1989).

Corwin, S. A. "Differences in Trading Behavior Across New York Stock Exchange Specialist Firms." Journal of Finance, forthcoming.

Demsetz, H. "The cost of transacting." Quarterly Journal of Economics, 82 (1968), 33-53.

Fishman, M. J. and F. A. Longstaff. "Dual Trading in Futures Markets." Journal of Finance, 47(1992), 643671.

Grossman, S. J. and M. H. Miller. "Liquidity and Market Structure." Journal of Finance, 43 (1988), 617-637. 
Grossman, S. J. "An Economic Analysis of Dual Trading." Rodney L. White Center for Financial Research Paper 33-89, The Wharton School, University of Pennsylvania (1989).

Hasbrouck, J. "Assessing the Quality of a Securities Market: A New Approach to Transaction-cost Measurement." Review of Financial Studies, 6 (1993), 191-212.

Kleidon, A. W. and R. D. Willig. "Why Do Christie and Schultz Infer Collusion From Their Data?" Working Paper, Cornerstone Research (1995).

Kuserk, G. and P. Locke. "Scalper Behavior on Futures Markets." Journal of Futures Markets, 13 (1993), 409431.

Kyle, A. S. "Continuous Auctions and Insider Trading." Econometrica, 53 (1985), 1315-1335.

Lee, C. M.C. "Market Integration and Price Execution for NYSE-listed Securities." Journal of Finance, 48 (1993), 1009-1038.

Leuthold, R. M.; P. Garcia; and R. Lu. "The Returns and Forecasting Ability of Large Traders in the Frozen Pork Bellies Futures Market.” Journal of Business, 67 (1994), 459-473.

Locke, P. and A. Sarkar. "Volatility and Liquidity in Futures Markets." Research Paper \#9612, Federal Reserve Bank of New York (1996).

Park, H.; A. Sarkar; and L. Wu. "Do Brokers Misallocate Customer Trades? Evidence from Futures Markets." Office for Futures and Options Research (OFOR) Paper Number 98-01, The University of Illinois at Urbana-Champaign (1998).

Roell, A. "Dual Capacity Trading and the Quality of the Market." Journal of Financial Intermediation, 1 (1990), 105-124.

Sarkar, A. "Dual trading: Winners, Losers and Market Impact." Journal of Financial Intermediation, 4 (1995), 77-93.

Smith, T. and R. E. Whaley. "Assessing the Cost of Regulation: The Case of Dual Trading." Journal of Law and Economics, 37 (1994), 329-36.

Spiegel, M. and A. Subrahmanyam. "Informed Speculation and Hedging in a Noncompetitive Securities Market." Review of Financial Studies, 5 (1992), 307-329.

Stoll, H. R. "Alternative views of market making." In Market Making and the Changing Structure of the Securities Industry, Amihud, T. Ho, and R. Schwartz, eds. Lexington Books (1985).

Walsh, M. J. and S. J. Dinehart. "Dual Trading and Futures Market Liquidity: An Analysis of Three Chicago Board of Trade Contract Markets." Journal of Futures Markets, 11 (1991), 519-537. 


\section{Footnotes}

1. In 1992, the U.S. Congress passed the Futures Trading Practice Act, which, among other things, compelled the Commodity Futures Trading Commission (CFTC) to pass regulations to prohibit dual trading on high volume contracts. The regulations allow affected exchanges to petition for relief based on 1) an acceptable audit trail (i.e., ability to track a floor traders' activities), or 2) a threat to the hedging utility and price discovery function of futures markets, should the practice of dual trading be prohibited.

2. Studies of dual trading featuring the bid-ask spread include the Commodity Futures Trading Commission (1989), Walsh and Dinehart (1991), Fishman and Longstaff (1992), Smith and Whaley (1994), and Chang and Locke (1996).

3. CME's top-step rule (Rule 541) states: A member, who has executed an S\&P 500 futures contract order while on the top step of the $S \& P 500$ futures pit, shall not thereafter on the same day trade $S \& P 500$ futures contracts for his account. Rule 552 banned dual trading in all "mature liquid" contracts (i.e., contracts with "daily average volume of 10,000 contracts or more...over the previous six month". As of December 1991, five commodities were affected by Rule 552: Pound Sterling, Swiss Franc, Japanese Yen, Deutsche Mark, and Eurodollars. Our choice of the Yen was determined by data availability. However, Chang and Locke (1996) show that the Yen is representative of the affected contracts.

While the two rules appear different, their effects on dual trading are similar. The top-step rule bans dual trading only on the top-step of the pit, while Rule 552 bans dual trading in all active contracts. However, the pit geography dictates that brokers stand on the top step of the pit to maintain sight contact with their clerks and the trading desk. Thus, the top-step rule severely constrains brokers from dual trading., as table one in our paper illustrates.

4. There is little academic research on the potential abuses from dual trading. An exception is Park, Sarkar and Wu (1998), who examine whether dual traders misallocate customer trades. An example of rising legislative interest in distributional issues is a recent bill in the U.S. Senate that proposes a relaxation of CFTC oversight of markets restricted to "professional" investors, defined as certain banks, companies and select individuals with assets of more than $\$ 10$ million. See the Wall Street Journal, February 10, 1997.

5. In Fishman and Longstaff (1992), the effect of dual trading on liquidity may or may not be negative. But, Sarkar (1995) shows that, if order size is variable, then dual trading may reduce liquidity. In Roell (1990), market liquidity is lower because 
of dual trading, although some uninformed traders are better off.

6. However, we leave open the possibility that an individual dual trader may be less skilled than an individual pure broker. This could happen if a floor trader made a mistake when deciding, on the basis of her skill level, whether to become a dual trader or a pure broker.

7. An implication of our assumptions is that, if dual trading is prohibited in a particular futures contract, some customers may no longer trade that contract, at least temporarily. Instead, they may trade a related futures contract or a related security, such as an options contract. Such behavior is optimal if investors allocate their wealth across different markets to achieve a particular risk-return combination, and are sensitive to the relative skill levels of brokers in these different markets.

8. Our condition ensures that hedgers do not "over hedge" their endowments (i.e., it is not the case that $\left|D_{i}\right|>1$ for $i=b, d$ ). As Spiegel and Subrahmanyam (1992) point out, "over hedging" occurs when the covariance between the price and the asset value is large. Although an interesting theoretical possibility, "over hedging" may be quite rare in practice.

Since equilibrium requires that $N_{1}>N_{2}$, our condition also implies $N_{2}>N_{3}$ In terms of the model's exogenous parameters, the inequality $N_{2}>N_{3}$ is likely to be satisfied for high values of $h$, and low values of $R, \Sigma_{\mathrm{w}}$ and $\Sigma_{v}$. Note that our existence condition imposes no restriction on the relationship between $N_{2}$ and $N_{3}$.

9. We thank the referee for bringing this issue to our attention.

10. The behavior of noise traders can be modeled, although this would add considerably to the model's complexity.

11. The four types are: trading for own account, trading for a clearing members' house account, trading for another member present on the exchange floor, and trading for any other type of customer.

12. The $2 \%$ filter is used to allow for the possibility of error trading. As Chang, Locke and Mann (1994) state, "when a broker makes a mistake in executing a customer order, the trade is placed into an error account as a trade for the broker's personal account. The broker may then offset the error with a trade for the error account. A value of $2 \%$ for this error trading seems reasonable from conversations with CFTC and exchange staff."

13. The difference in the size of the pre-rule and post-rule samples arises because the two regulatory events do not fall exactly in the middle of our sample period.

14. In particular, trades maintained in traders' error accounts appear identical to proprietary trading in the data set. This 
error account trading, combined with customer trading, will appear to be dual trading in the post-restriction period.

15. Since the number of broker days for dual-locals and dual-quitters is small, we cannot obtain meaningful estimates of customer trading costs for these groups separately. 


\section{APPENDIX}

\section{Proof of Lemma 1.}

The profits of the j-th hedger is:

$$
H_{j, d}=v\left(u_{j, d}+w_{j}\right)-\lambda_{d} u_{j, d}\left(u_{j, d}+D_{d} \sum_{m \neq j}^{\alpha h} w_{m}+z+x_{d}\right)
$$

The $\mathrm{j}$-th hedger chooses $u_{j, d}$ to maximize certainty equivalent profits:

$$
G_{j, d}=E\left(H_{j, d} \mid w_{j}\right)-(R / 2) \operatorname{Var}\left(H_{j, d} \mid w_{j}\right) .
$$

From the proof of proposition 3 in Sarkar (1995), $D_{d}$ is given implicitly by (after replacing $h$ by $\alpha h)$ :

$$
\begin{gathered}
R D_{d} \frac{\left(\lambda_{d} D_{d}\right)^{2}}{4}(\alpha h-1) \Sigma_{w}+ \\
D_{d}\left[\lambda_{d}+R \Sigma_{v}\left(1-\frac{n t(Q+2)}{(1+Q)^{2}}\right)\right]+R \Sigma_{v} \frac{(2-t)}{(1+Q)}=0
\end{gathered}
$$

Given her observations of $\left\{x_{1, d}, ., x_{n, d} ; u_{l, d}, \ldots, u_{\alpha h, d}\right\}$, the dual trader chooses her trade $z$ to maximize expected profits $\Pi_{d}=E\left[\left\{\left(v-p_{d}\right) z\right\} \mid\left\{x_{1, d}, \ldots, x_{n, d} ; u_{1, d}, ., u_{\alpha h, d}\right\}\right]$. Let $E\left(v \mid\left\{x_{1, d}, \ldots, x_{n, d}\right\}\right)=b x_{d}$. From the first-order condition of the dual trader's maximization problem:

$$
z=\frac{\left(b-\lambda_{d}\right) x_{d}}{2 \lambda_{d}}-\frac{u_{d}}{2}
$$

Informed customer $i$ chooses her trade $x_{i, d}$ to maximize expected profits:

$$
\Pi_{I}=E\left[\left\{\left(v-p_{d}\right) x_{i, d}\right\} \mid s_{i}\right]
$$

conditional on $s_{i}$, and the dual trader's optimal trading rule $z\left(x_{d}, u_{d}\right)$. From Bayes' rule, $b=t /\left(A_{d} Q\right)$ and $E\left(s_{j} \mid s_{i}\right)=t s_{i}$ for $j \neq i$. Incorporating (A3) and substituting for $b$ in $\Pi_{I}$ and solving for $x_{d}$, we get: 


$$
x_{d}=A_{d} s, \text { where } A_{d}=\frac{t(Q-1)}{\lambda_{d} Q(1+Q)}
$$

From (A3) and (A4):

$$
y_{d}=\frac{t}{(1+Q) \lambda_{d}} s+\frac{u_{d}}{2} \text {, where } s=\sum_{i=1}^{n} s_{i} \text {. }
$$

(3) follows from solving $\lambda_{d}=\operatorname{cov}\left(v, y_{d}\right) / \operatorname{var}\left(v, y_{d}\right)$. From (3) and (A2), we get (5), (6) and (7).

\section{Proof of Lemma 2.}

See the proof of lemma 3 in Sarkar (1995).

\section{Proof of Proposition 1.}

We first prove the following lemmas.

Lemma A1. $d D_{d} / d / \alpha$ is strictly increasing in $\sqrt{\alpha}$ if $\left(N_{2}\right)^{2}>N_{1} N_{3}$.

Proof: Since $D_{d}=\sqrt{\alpha}\left[\sqrt{ } \alpha N_{1}-N_{2}\right] /\left[\alpha N_{1}-N_{3}\right]$,

$$
d D_{d} / d \sqrt{ } \alpha=\left[\sqrt{ } \alpha N_{1}-N_{2}\right] /\left[\alpha N_{1}-N_{3}\right]+\left[\sqrt{\alpha} \alpha N_{1} /\left(\alpha N_{1}-N_{3}\right)^{2}\right]\left[-N_{3}+2 \sqrt{ } \alpha N_{2}-\alpha N_{1}\right]
$$

The first term above is positive if the equilibrium conditions $\sqrt{\alpha} N_{1}>N_{2}$ and $\alpha N_{1}>N_{3}$ are satisfied.

The roots of $\left[-N_{3}+2 \sqrt{ } \alpha N_{2}-\alpha N_{1}\right]=0$ are:

$$
\sqrt{\alpha}=\frac{N_{2}}{N_{1}} \pm \frac{1}{N_{1}} \sqrt{N_{1} N_{3}-N_{2}^{2}}
$$

Evaluated at $\sqrt{ } \alpha=N_{2} / N_{1}<1, d D_{d} / d \sqrt{ } \alpha=N_{2}>0$.

From (A6), $d D_{d} / d V \alpha=0$ has no real roots when $\left(N_{2}\right)^{2}>N_{l} N_{3}$. Thus, $d D_{d} / d V \alpha$ can never change sign and is always positive for $\alpha>1$. 
Lemma A2. (i) $\left|D_{d}\right|=\left|D_{b}\right|$ if $\alpha=1$. (ii) $\left|D_{d}\right|>\left|D_{b}\right|$ if $\alpha>1$ and $\left(N_{2}\right)^{2}>N_{l} N_{3}$.

Proof. Part (i) follows from definition. Part (ii) follows from part (i) and lemma A1.

Now we prove the proposition.

(i) Unconditional expected profits of the informed trader in the dual trading model are $A_{d} \sqrt{ } /[2(1+Q)]$ and, from (1), $A_{d}$ is increasing in $\alpha$.

(ii) From (3), $\lambda_{d}$ is decreasing in $\alpha$ if $\left|D_{d}\right|$ increases with $\alpha$.

(iii) The utility of the $j$-th hedger in the dual trading model is (after dividing through by $\left(w_{j}\right)^{2}$ and adding a constant term to normalize):

$$
\begin{aligned}
\frac{G_{j, d}}{\left(w_{j}\right)^{2}}+\frac{R \Sigma_{v}}{2} & =-\frac{\lambda_{d}}{2}\left(D_{d}\right)^{2} \\
& \left.-\frac{R}{2}\left(\left(D_{d}\right)^{2} \mid \Sigma_{\nu}\left(1-\frac{n t(2+Q)}{(1+Q)^{2}}\right)+\left(\lambda_{d} D_{d}\right)^{2}(\alpha h-1) \frac{\Sigma_{w}}{4}\right]\right) \\
& +\frac{R \Sigma_{v}(2-t)\left|D_{d}\right|}{1+Q}
\end{aligned}
$$

Denote by $S_{1}$ the sum of the second and last terms on the right-hand side (RHS) of (A7):

$$
S_{1}=-\frac{R \Sigma_{v}}{2}\left(D_{d}\right)^{2}\left(1-\frac{n t(2+q)}{(1+Q)^{2}}\right)+R \Sigma_{v}\left(-D_{d}\right) \frac{2-t}{1+Q}
$$

Taking derivative of $S_{1}$ with respect to $\sqrt{ } \alpha$ :

$$
\frac{d S_{1}}{d \sqrt{\alpha}}=\frac{d\left|D_{d}\right|}{d \sqrt{\alpha}} R \Sigma_{\nu}\left(D_{d}\left[1-\frac{n t(2+Q)}{(1+Q)^{2}}\right]+\frac{2-t}{1+Q}\right)
$$

Given $\left(N_{2}\right)^{2}>N_{I} N_{3}, d D_{d} / d V \alpha>0$. The first term in parenthesis is negative, since $D_{d}<0$ and 
the term in square brackets is positive. The second term in parenthesis is positive. We show below that the sum of the two terms in parenthesis is positive.

First, we note that $\left|D_{d}\right|<1$. This follows because $N_{1}>N_{2}$ in equilibrium which implies $N_{2}>$ $N_{3}$, since $\left(N_{2}\right)^{2}>N_{1} N_{3}$. In addition, $\alpha>1$. Since $\left|D_{d}\right|=\left[\alpha N_{1}-\sqrt{\alpha} N_{2}\right] /\left[\alpha N_{1}-N_{3}\right]$, these facts imply $\left|D_{d}\right|<1$

Second, the expression $(2-t) /(1+Q)+1-[n t(2+Q)] /\left[(1+Q)^{2}\right]$ sums to:

$$
\frac{(2-t)(1+Q)+(1+Q)^{2}-n t(2+Q)}{(1+Q)^{2}}
$$

Consider the numerator of (A10). Make the substitution $n t=(1+Q)-2 t$. The value of the numerator is: $(2-t)(1+Q)+(1+Q)^{2}-(1+Q)(2+Q)+(2-t)(2+Q)>(2-t)(1+Q)+\left(1^{2}+Q\right)-$ $(1+Q)(2+Q)+(2+Q)=4+2 Q>0$. Thus, the positive term in the parenthesis dominates the negative term, and $d S_{1} / d \sqrt{\alpha}>0$.

From (3) and (6), we can write $\left(-\lambda_{d} D_{d}\right)=c / \alpha$, where $c=N_{2} /(1+Q)>0$.

Denote by $S_{2}$ the sum of the first and third terms of (A7):

$$
S_{2}=\frac{c D_{d}}{\sqrt{\alpha}}-\frac{R c^{2}}{2 \alpha}\left(D_{d}\right)^{2}(\alpha h-1) \Sigma_{w}
$$

Taking the derivative of $S_{2}$ with respect to $\sqrt{ } \alpha$ : 


$$
\begin{aligned}
\frac{d S_{2}}{d \sqrt{\alpha}} & =\frac{c}{\sqrt{\alpha}}\left(\frac{d D_{d}}{d \sqrt{\alpha}}-\frac{D_{d}}{\sqrt{\alpha}}\right) \\
& +\frac{c}{\sqrt{\alpha}}\left(\frac{R c}{\alpha}\left(D_{d}\right)^{2}(\alpha h-1) \Sigma_{w}-R \frac{c}{\sqrt{\alpha}} D_{d} \frac{d D_{d}}{d \sqrt{\alpha}}(\alpha h-1) \Sigma_{w}-R \operatorname{ch}\left(D_{d}\right)^{2} \Sigma_{w}\right)
\end{aligned}
$$

Next, define $\left(D_{d}\right)=\left[N_{2}-\sqrt{ } \alpha N_{1}\right] /\left[\alpha N_{1}-N_{3}\right]$. Therefore, $D_{d} / \sqrt{ } \alpha=D_{d}$ and $d D_{d} / d V \alpha=D_{d} / N \alpha$ $+\sqrt{ } \alpha\left(d D_{d} / d \vee \alpha\right)$. Substituting for $d D_{d} / d \sqrt{ } \alpha$ in (A12):

$$
\begin{aligned}
\frac{d S_{2}}{d \sqrt{\alpha}} & =c \frac{d D_{d}}{d \sqrt{\alpha}} \\
& +\frac{c}{\sqrt{\alpha}}\left(R \Sigma_{w} c\right)\left(-D_{d}\right)\left[(\alpha h-1) \frac{d D_{d}^{\prime}}{d \sqrt{\alpha}}+h D_{d}\right]
\end{aligned}
$$

In the following lemma, we derive sufficient conditions to ensure $d\left(D_{d}\right) / d V \alpha>0$, which is a necessary condition for $d S_{2} / d V \alpha>0$.

Lemma A3. Let $N_{2}-\left(N_{1} N_{3}\right)^{1 / 2}=k>0$. If $k>\left[\left(\alpha N_{1}\right)^{1 / 2}-N_{3}\right]^{2} / 2 \sqrt{\alpha}$, then $d\left(D_{d}\right) / d \sqrt{ } \alpha>0$.

Proof: $d\left(D_{d}\right) / d \vee \alpha$ evaluated at $N_{2}-\left(N_{1} N_{3}\right)^{1 / 2}=k$ is:

$$
\frac{d D_{d}}{d \sqrt{\alpha}}=\frac{N_{1}}{\left(\alpha N_{1}-N_{3}\right)^{2}}\left[2 \sqrt{\alpha}\left(k+\sqrt{N_{1} N_{3}}\right)-N_{3}-\alpha N_{1}\right]
$$

The RHS of (A14) is positive if $k>\left[\left(\alpha N_{l}\right)^{1 / 2}-N_{3}\right]^{2} / 2 \sqrt{\alpha}$.

If (A14) is satisfied, the only negative term in (A13) is $-(c / \sqrt{\alpha})\left(R{ }_{w} c\right) h\left(D_{d}\right)^{2}$. Next, we show this term is bounded from above in absolute value, as follows. To derive the upper bound on $(c / \sqrt{\alpha})\left(R{ }_{w} c\right) h\left(D_{d}\right)^{2}$, note that $\left(D_{d}\right)^{2} / \sqrt{\alpha}<1$ because $\sqrt{\alpha} \quad 1$ and, as shown earlier, $\left(D_{d}\right)^{2}<1$. In the next lemma, we compute an upper bound on $c^{2}\left(R_{w}\right) h$. 
Lemma A4. $h R{ }_{w} c^{2}<4 \sqrt{ }\left(2 \Sigma_{\mathrm{v}}\right) / \sqrt{ } \Sigma_{\mathrm{w}}$.

Proof: $\left(N_{2}\right)^{2}>N_{l} N_{3}$ implies:

$$
2>R \frac{\sqrt{\Sigma_{v} \Sigma_{w}(2-t)}}{\sqrt{(1+Q)}}
$$

From the definition of $c$ :

$$
\begin{aligned}
R \Sigma_{w} h c^{2} & =4 R \Sigma_{v} \frac{n t}{(1+Q)^{2}} \\
& <\frac{4 R \Sigma_{v}}{(1+Q)} \\
& <\frac{8 \sqrt{\Sigma_{v}}}{\sqrt{(1+Q) \Sigma_{w}(2-t)}} \\
& <\frac{4 \sqrt{2 \Sigma_{v}}}{\sqrt{\Sigma_{w}}}
\end{aligned}
$$

The first inequality follows because $(1+Q)>n t$, the second inequality follows from (A15), and the final inequality follows from $Q 1$ and $t 1$. We note that as the ratio $\Sigma_{\sqrt{ }} / \Sigma_{\mathrm{w}}$ becomes large, $N_{2}$ becomes large, $D_{d}$ becomes small and, consequently, the negative term $(c / \sqrt{\alpha})\left(c R{ }_{w}\right) h\left(D_{d}\right)^{2}$ cannot become arbitrarily large. Hence, at some value of $k$ large enough, the positive term $d\left(D_{d}\right) / d \vee \alpha$ will outweigh the negative term in (A13). To show that at least one such value of $k$ exists, choose $N_{l}=N_{2}+$, and $\alpha=1+$, where and are positive and arbitrarily small. At these values, $k$ is positive and finite, but $D_{d}$ is arbitrarily small, and so the negative term $(c / \sqrt{\alpha})\left(R_{w} c\right) h\left(D_{d}\right)^{2}$ is arbitrarily small.

Hence, if lemma A3 is satisfied, both $S_{1}$ and $S_{2}$ are increasing monotonically with respect to $\alpha$, and hedger $j$ 's expected utility is higher with the dual trader. This completes the proof. 


\section{Proof of Proposition 2.}

(i) Suppose $V_{\alpha=1}$. From lemma A2, $\left|D_{b}\right|=\left|D_{d}\right|$. From (11), $\left(1 / \lambda_{d}\right)<\left(1 / \lambda_{b}\right)$. If $\sqrt{ } \alpha=2$, then $\left(1 / \lambda_{d}\right)>\left(1 / \lambda_{b}\right)$ since, from lemma A2, $\left|D_{d}\right|>\left|D_{b}\right|$ when $\alpha>1$.

(ii) $\left(1 / \lambda_{d}\right)=\left(1 / \lambda_{b}\right)$ if and only if $\sqrt{ } \alpha\left|D_{d}\right|-2\left|D_{b}\right|=0$. Substituting for $\left|D_{b}\right|$ and $\left|D_{d}\right|$ from (4) and (10):

$$
\begin{gathered}
\sqrt{\alpha}\left|D_{d}\right|-2\left|D_{b}\right|= \\
(\sqrt{\alpha})^{3} N_{1}\left(N_{1}-N_{3}\right)+(\sqrt{\alpha})^{2}\left[N_{2}\left(N_{1}+N_{3}\right)-2\left(N_{1}\right)^{2}\right]+2 N_{3}\left(N_{1}-N_{2}\right) \\
\left(\alpha N_{1}-N_{3}\right)\left(N_{1}-N_{3}\right)
\end{gathered}
$$

The numerator on the RHS of (A17) is a cubic equation in $\sqrt{ } \alpha$. We show that there exists at least one real root $(\sqrt{ } \alpha)$ to this cubic equation, satisfying $1<(\sqrt{ } \alpha)<2$. Let:

$$
\begin{aligned}
& a=N_{1}\left(N_{1}-N_{3}\right)>0 \\
& b=N_{2}\left(N_{1}+N_{3}\right)-2\left(N_{1}\right)^{2}<0 \\
& d=2 N_{3}\left(N_{1}-N_{2}\right)>0
\end{aligned}
$$

Make the substitution $\sqrt{ } \alpha=(1+2 y)(-b / 3 a)$, and note that $\alpha$ and $y$ are positively correlated. Then the numerator on the RHS of (A17) can be rewritten as:

$y^{3}-(0.75) y=(0.25)$, where $=(13.5) a^{2} d /|b|^{3}-1$

\section{(A21)}

and where $|b|$ denotes the absolute value of $b$. We use Cardano's formula (Abramowitz and Stegun, 1970, page 17) to solve for the roots of (A21). Define $q=-(0.25)$ and $r=-/ 8$. Further, define: 


$$
\begin{aligned}
& s_{1}=\left[r+\left(q^{2}+r^{3}\right)^{1 / 2}\right]^{1 / 3} \\
& s_{2}=\left[r-\left(q^{2}+r^{3}\right)^{1 / 2}\right]^{1 / 3}
\end{aligned}
$$

Denoting $i$ as the complex number $\sqrt{(-1)}$, the roots of (A21) can be written as:

$$
\begin{aligned}
& z_{1}=s_{1}+s_{2} \\
& z_{2}=-(0.5)\left(s_{1}+s_{2}\right)+\frac{i \sqrt{3}}{2}\left(s_{1}-s_{2}\right) \\
& z_{3}=-(0.5)\left(s_{1}+s_{2}\right)-\frac{i \sqrt{3}}{2}\left(s_{1}-s_{2}\right)
\end{aligned}
$$

Next, we show that, given $\alpha \quad 1$, any real root $(\sqrt{ } \alpha)$ of (A17) must satisfy $1<(\sqrt{ } \alpha)<2$. To do so, we note that, given $N_{2}>\left(N_{1} N_{3}\right)^{1 / 2}$, and $N_{1}>N_{2}>N_{3}$, the range of values for $N_{2} \quad\left(\sqrt{ } N_{1} \sqrt{ } N_{3}\right.$, $\left.N_{1}\right)$.

For the lower limit on $(\sqrt{ } \alpha)$, let $N_{2}=N_{1}-\quad$, where $>0$ and arbitrarily small. As 0 , $b \quad(-a)$ and $d \quad 0$. Therefore, $\quad-1,(b / a) \quad-1, r \quad 1 / 8,\left(q^{3}+r^{2}\right) \quad 0, s_{1} \quad 0.5$ and $s_{2} \quad 0.5$. Thus, $z_{1} \quad 1$, while $z_{2}=z_{3}<0$. Consequently, $(\sqrt{ } \alpha)=(1+2 y)(-b / 3 a) \quad(1+2) /(3)=1$.

For the upper limit on $(\sqrt{ } \alpha)$, let $N_{2}-\sqrt{ } N_{1} \sqrt{ } N_{3}=$ and, further, let $N_{3}$, where $>0,>0$ and both are arbitrarily small. As $\quad 0, a\left(N_{1}\right)^{2}, b(-2 a), d \quad 0$. Therefore, $\quad-1,(b / a)-2, r \quad 1 / 8$, $\left(q^{3}+r^{2}\right) \quad 0, s_{1} \quad 0.5$ and $s_{2} \quad 0.5$. Thus, $z_{1} \quad 1$, while $z_{2}=z_{3}<0$. Consequently, $(\sqrt{ } \alpha) \quad(1+2) 2 /(3)=2$.

\section{Proof of Corollary 1.}

Since $\sqrt{ } \alpha$ is positively related to $y$ (defined in the previous proof), we will show that $y$ is negatively related to $N_{2}$, the price impact of hedger trades. In fact, it is sufficient to show that (defined in A21) is negatively related to $N_{2}$. 
Taking the derivative of with respect to $\mathrm{N}_{2}$ :

$$
\begin{aligned}
\frac{T}{N_{2}} & =\frac{27 N_{3} a^{2} b^{2}}{b^{6}}\left[-b-3\left(N_{1}-N_{2}\right)\left(N_{1}-N_{3}\right)\right] \\
& =\frac{27 N_{3} a^{2} b^{2}}{b^{6}}\left[-N_{1}\left(N_{1}+3 N_{3}\right)+2 N_{2}\left(N_{1}+N_{3}\right)\right]
\end{aligned}
$$

Thus, $\quad / N_{2}<0$ if:

$$
N_{2}<N_{1}\left(N_{1}+3 N_{3}\right) / 2\left(N_{1}+N_{3}\right)
$$

Since $\left(N_{1}+3 N_{3}\right) / 2\left(N_{1}+N_{3}\right)<1$, the condition requires that $N_{2}$ is sufficiently less than $N_{l}$.

\section{Proofs of examples 1 and 2.}

The proofs are contained in the proof of proposition 2.

\section{Proof of Proposition 3.}

(i) Define dual trader's expected trading volume as $\mathrm{E}(|z|)$, which is proportional to the standard deviation of $z$. Since $z=\left[x_{d} /(Q-1)\right]-u_{d}(0.5)$, after substituting for $x_{d}$, the variance of $z$ is:

$$
\operatorname{var}(z)=\left[(0.25) h{ }_{w}(\mathbf{1}+Q) / Q\right] \alpha\left(\boldsymbol{D}_{d}\right)^{2}, \text { which is increasing in } \alpha \text { if } N_{2}>\left(N_{l} N_{3}\right)^{1 / 2} \text {. }
$$

(ii) Dual trader's unconditional expected revenues are $\mathrm{E}\left[\left(v-p_{d}\right) z\right]$. In equilibrium:

$$
\begin{aligned}
E\left[\left(v-p_{d}\right) z\right] & =E\left[\left(v-\frac{\lambda_{d} x_{d} Q}{Q-1}-\frac{\lambda_{d} u_{d}}{2}\right)\left(\frac{1}{Q-1} x_{d}-\frac{u_{d}}{2}\right)\right] \\
& =\sqrt{\alpha h}\left|D_{d}\right|\left(\frac{1}{2 Q} \sqrt{n t \Sigma_{w} \Sigma_{v}}\right)
\end{aligned}
$$

The terms in parenthesis are independent of $\alpha$. Thus, as long as $\left|D_{d}\right|$ is increasing in $\alpha$, dual 
trader's revenues are increasing in $\alpha$. 
Table 1

Trading Activity Before and After Dual Trading Restrictions

\begin{tabular}{|c|c|c|c|c|c|c|c|c|}
\hline \multirow[b]{2}{*}{ Number of } & \multicolumn{2}{|c|}{ Local days } & \multicolumn{2}{|c|}{ Broker days } & \multicolumn{2}{|c|}{ Dual trading days } & \multicolumn{2}{|c|}{ All } \\
\hline & Before & After & Before & After & Before & After & Before & After \\
\hline & \multicolumn{8}{|c|}{ S\&P 500} \\
\hline Trader days & 8,934 & 8,989 & 1,560 & 2,693 & 3,173 & 1,037 & 13,667 & 12,719 \\
\hline Trades & 483,428 & 513,677 & 84,176 & 274,441 & 458,283 & 107,892 & $1,025,887$ & 896,010 \\
\hline own account & 483,428 & 513,677 & ----- & ----- & 135,684 & 41,254 & 619,157 & 554,886 \\
\hline customer & ----- & ----- & 84,176 & 274,441 & 322,599 & 66,638 & 406,730 & 341,124 \\
\hline Volume & $1,396,106$ & $1,474,505$ & 425,652 & 936,266 & $1,632,196$ & 324,375 & $3,453,954$ & $2,735,146$ \\
\hline own account & $1,396,106$ & $1,474,505$ & ----- & ----- & 538,050 & 122,927 & $1,934,184$ & $1,597,431$ \\
\hline customer & ----- & ----- & 425,652 & 936,266 & $1,094,146$ & 201,448 & $1,519,770$ & $1,137,715$ \\
\hline Daily trades: & 13,812 & 17,713 & 2,405 & 9,463 & 13,094 & 3,721 & 29,311 & 30,897 \\
\hline own account & 13,812 & 17,713 & ----- & ----- & 3,877 & 1,423 & 17,690 & 19,134 \\
\hline customer & ----- & ----- & 2,405 & 9,463 & 9,217 & 2,298 & 11,621 & 11,763 \\
\hline Daily volume: & 39,889 & 50,845 & 12,161 & 32,285 & 46,634 & 11,185 & 98,684 & 94,316 \\
\hline own account & 39,889 & 50,845 & ----- & ----- & 15,373 & 4,239 & 55,262 & 55,084 \\
\hline \multirow[t]{2}{*}{ customer } & ----- & ----- & 12,161 & 32,285 & 31,261 & 6,946 & 43,422 & 39,232 \\
\hline & \multicolumn{8}{|c|}{ Japanese Yen } \\
\hline Trader days & 2,241 & 1,435 & 971 & 910 & 563 & 135 & 3,775 & 2,480 \\
\hline Trades & 128,910 & 64,407 & 65,298 & 49,215 & 59,399 & 7,261 & 253,607 & 120,883 \\
\hline own account & 128,910 & 64,407 & ----- & ----- & 14,562 & 1,564 & 143,452 & 65,976 \\
\hline customer & ---- & ----- & 65,298 & 49,215 & 44,837 & 5,697 & 110,155 & 54,907 \\
\hline Volume & 558,528 & 297,661 & 374,240 & 339,488 & 309,749 & 36,166 & $1,242,517$ & 673,315 \\
\hline own account & 558,528 & 297,661 & ----- & ----- & 47,385 & 5,819 & 605,637 & 303,473 \\
\hline customer & ----- & ----- & 374,240 & 339,488 & 262,364 & 30,347 & 636,880 & 369,842 \\
\hline Daily trades: & 3,683 & 2,221 & 1,866 & 1,697 & 1,697 & 250 & 7,246 & 4,168 \\
\hline own account & 3,683 & 2,221 & ----- & ----- & 416 & 54 & 4,099 & 2,275 \\
\hline customer & ----- & ----- & 1,866 & 1,697 & 1,281 & 196 & 3,147 & 1,893 \\
\hline Daily volume & 15,958 & 10,264 & 10,693 & 11,706 & 8,850 & 1,247 & 35,501 & 23,218 \\
\hline own account & 15,958 & 10,264 & ----- & ----- & 1,354 & 201 & 17,304 & 10,465 \\
\hline customer & ---- & ---- & 10,693 & 11,706 & 7,496 & 1,046 & 18,197 & 12,753 \\
\hline
\end{tabular}

Local (broker) days are days on which floor traders traded exclusively for their own (customers') accounts. Dual trading days are days when floor traders traded both for their own accounts and for customers. There are 35 days before and 29 days after the dual trading restrictions. The sample periods are May 1 to July 31, 1987 for the S\&P 500 and April 1 to June 28, 1991 for the Japanese Yen. 
Table 2

Realized Bid-ask Spreads Before and After Dual Trading Restrictions S\&P 500 and Japanese Yen Futures

\begin{tabular}{lllll}
\hline \multicolumn{5}{c}{ S\&P 500 Futures } \\
\hline$a_{0}$ & $a_{1}$ & $a_{2}$ & $a_{3}$ & $a_{4}$ \\
\hline $\begin{array}{l}20.21^{\star} \\
(3.44)\end{array}$ & $\begin{array}{l}-0.0005^{\star} \\
(-2.007)\end{array}$ & $\begin{array}{l}0.168^{\star} \\
(4.128)\end{array}$ & $\begin{array}{l}-0.03 \\
(-0.81)\end{array}$ & $\begin{array}{l}4.74 \\
(1.304)\end{array}$ \\
\hline$N=64$ & $F=11.083$ & Prob $>F=0.001$ & \\
\hline \multicolumn{5}{c}{ Japanese Yen Futures } \\
\hline-1.62 & -0.0001 & $\begin{array}{l}1129.3^{\star} \\
(2.47)\end{array}$ & $\begin{array}{l}0.04 \\
(1.25)\end{array}$ & 0.07 \\
\hline-1.334$)$ & $(-0.332)$ & $0.079)$ \\
\hline$N=64$ & $F=5.036$ & Prob $>F=0.0015$ & \\
\hline
\end{tabular}

Changes in customer trading costs due to dual trading restrictions are estimated from the following regression:

$$
S_{t}=a_{0}+a_{1} V_{t}+a_{2} V O L_{t}+a_{3} M_{t}+a_{4} D_{t}+e_{t}
$$

where, for day $t, S_{t}$ is the measure of customer trading costs (average buy price minus average sale price) in dollars, $V_{t}$ is customer trading volume, $V O L_{t}$ is the standard deviation of buy prices for customer trades, $M_{t}$ is the number of floor traders trading for their own account, and $D_{t}=1$ in the pre-rule periods and 0 otherwise. T-statistics are shown in parentheses. Estimates significant at the 10 per cent level are starred. $N$ is the number of observations. The sample periods are May 1 to July 31, 1987 for the S\&P 500 and April 1 to June 28, 1991 for the Japanese Yen. 
Table 3

\section{Customer Price Impact Before and After Dual Trading Restrictions S\&P 500 and Japanese Yen Futures}

\begin{tabular}{lllll}
\hline \multicolumn{5}{c}{ S\&P 500 Futures } \\
\hline$a_{0}$ & $a_{1}$ & $a_{2}$ & $a_{3}$ & $a_{4}$ \\
\hline $\begin{array}{l}35.77 \\
(1.65)\end{array}$ & $\begin{array}{l}-0.00007 \\
(0.015)\end{array}$ & $\begin{array}{l}-44.08 \\
(-0.829)\end{array}$ & $\begin{array}{l}0.036 \\
(0.28)\end{array}$ & $\begin{array}{l}-6.87 \\
(-1.511)\end{array}$ \\
\hline$N=64$ & $F=1.05$ & Prob $>F=0.389$ & \\
\hline \multicolumn{7}{c}{ Japanese Yen Futures } \\
\hline 0.362 & -0.0004 & -3.515 & $0.23^{\star}$ \\
$(0.078)$ & $(-0.277)$ & $(-0.23)$ & $(1.84)$ & $(0.872)$ \\
\hline$N=64$ & $F=4.157$ & Prob $>F=0.0049$ & & \\
\hline
\end{tabular}

Changes in customer trading costs due to dual trading restrictions are estimated from the following regression:

$$
P I M_{t}=a_{0}+a_{1} V_{t}+a_{2} V O L_{t}+a_{3} M_{t}+a_{4} D_{t}+e_{t}
$$

where, for day $t, P I M_{t}$ is a measure of the price impact of customer trades (daily average of the price change for customer trades divided by the net customer trading volume in each trading bracket) in dollars, $V_{t}$ is customer trading volume, $V O L_{t}$ is the standard deviation of buy prices for customer trades, $M_{t}$ is the number of floor traders trading for their own account, and $D_{t}=1$ in the pre-rule periods and 0 otherwise. $T$-statistics are shown in parentheses. Estimates significant at the 10 per cent level are starred. $N$ is the number of observations. The sample periods are May 1 to July 31, 1987 for the S\&P 500 and April 1 to June 28, 1991 for the Japanese Yen. 
Table 4

Floor Trader Transition: S\&P 500 and Japanese Yen Futures

\begin{tabular}{|c|c|c|c|c|c|}
\hline \multirow[b]{2}{*}{$\begin{array}{l}\text { Pre-restriction } \\
\text { choice }\end{array}$} & \multicolumn{5}{|c|}{ Panel A: Post-restriction choice for all floor traders } \\
\hline & Pure broker & Local & Dual trader & Discontinued & $\begin{array}{l}\text { Pre-restriction } \\
\text { total }\end{array}$ \\
\hline \multicolumn{6}{|c|}{ S\&P 500} \\
\hline Pure broker & 52 & 8 & 5 & 140 & 205 \\
\hline Local & 7 & 325 & 36 & 116 & 484 \\
\hline Dual trader & 14 & 61 & 149 & 20 & 244 \\
\hline $\begin{array}{l}\text { Post-restriction } \\
\text { total } \\
\end{array}$ & 73 & 394 & 190 & 276 & 933 \\
\hline \multicolumn{6}{|c|}{ Japanese Yen } \\
\hline Pure broker & 38 & 0 & 1 & 67 & 106 \\
\hline Local & 1 & 80 & 2 & 46 & 129 \\
\hline Dual trader & 4 & 12 & 30 & 6 & 52 \\
\hline $\begin{array}{l}\text { Post-restriction } \\
\text { total } \\
\end{array}$ & 43 & 92 & 33 & 119 & 287 \\
\hline \multicolumn{6}{|c|}{ Panel B: Post-restriction choice for active floor traders } \\
\hline $\begin{array}{l}\text { Pre-restriction } \\
\text { choice }\end{array}$ & Pure broker & Local & Dual trader & Discontinued & $\begin{array}{l}\text { Pre-restriction } \\
\text { total }\end{array}$ \\
\hline \multicolumn{6}{|c|}{ S\&P 500} \\
\hline Pure broker & 31 & 1 & 4 & 9 & 45 \\
\hline Local & 0 & 305 & 32 & 51 & 388 \\
\hline Dual trader & 14 & 61 & 149 & 10 & 234 \\
\hline $\begin{array}{l}\text { Post-restriction } \\
\text { total }\end{array}$ & 45 & 367 & 185 & 70 & 667 \\
\hline \multicolumn{6}{|c|}{ Japanese Yen } \\
\hline Pure broker & 23 & 0 & 1 & 10 & 34 \\
\hline Local & 0 & 71 & 2 & 10 & 83 \\
\hline Dual trader & 4 & 11 & 30 & 3 & 48 \\
\hline $\begin{array}{l}\text { Post-restriction } \\
\text { total }\end{array}$ & 27 & 82 & 33 & 23 & 165 \\
\hline
\end{tabular}

Floor traders are classified in a 35 day period before dual trading restrictions according to whether they were pure brokers, locals or dual traders. These same floor traders are separately classified in a 29 day period after dual trading restrictions according to the same criteria and whether they continued to trade in the affected contract. In panel B, active floor traders are those who traded on at least two days in the pre-restriction period. Some floor traders were dual traders before restrictions, but traded as pure brokers on some days and as locals on other days following the restrictions. These floor traders are omitted from the samples. The sample periods are May 1 to July 31, 1987 for the S\&P 500 and April 1 to June 28, 1991 for the Japanese Yen. 
Table 5

Activity of Dual Traders who Changed Occupations or Quit

S\&P 500 and Japanese Yen Futures

\begin{tabular}{|c|c|c|c|c|c|c|c|c|c|c|c|}
\hline \multirow{3}{*}{$\begin{array}{l}\text { Trader Day } \\
\text { Type }\end{array}$} & \multicolumn{4}{|c|}{ Dual-brokers } & \multicolumn{4}{|c|}{ Dual-locals } & \multirow{2}{*}{\multicolumn{3}{|c|}{$\begin{array}{c}\text { Dual-quitters } \\
\text { Before }\end{array}$}} \\
\hline & \multicolumn{3}{|c|}{ Before } & \multirow{2}{*}{$\begin{array}{c}\text { After } \\
\text { Broker }\end{array}$} & \multicolumn{3}{|c|}{ Before } & \multirow{2}{*}{$\begin{array}{l}\text { After } \\
\text { Local } \\
\end{array}$} & & & \\
\hline & Local & Broker & Dual & & Local & Broker & Dual & & Local & Broker & Dual \\
\hline \multicolumn{12}{|c|}{ S\&P 500} \\
\hline Trader days & 24 & 102 & 135 & 204 & 892 & 31 & 352 & 1,075 & 146 & 13 & 107 \\
\hline Transactions & 127 & 6,318 & 18,798 & 18,108 & 57,347 & 567 & 36,062 & 59,433 & 5,805 & 234 & 9,582 \\
\hline Volume & 345 & 32,344 & 95,166 & 72,260 & 165,705 & 1,786 & 151,524 & 166,580 & 17,685 & 1,701 & 23,963 \\
\hline $\begin{array}{l}\text { Average daily } \\
\text { trades: }\end{array}$ & 5.29 & 61.94 & 139.24 & 88.76 & 64.29 & 18.29 & 102.45 & 55.29 & 39.76 & 18 & 89.55 \\
\hline own account & 5.29 & ----- & 18.96 & ---- & 64.29 & ----- & 55.16 & 55.29 & 39.76 & ----- & 35.93 \\
\hline customer & ---- & 61.94 & 120.29 & 88.76 & ---- & 18.29 & 47.29 & ---- & ---- & 18 & 53.62 \\
\hline $\begin{array}{l}\text { Average daily } \\
\text { volume: }\end{array}$ & 14.38 & 317.1 & 704.93 & 354.22 & 185.77 & 57.61 & 430.47 & 154.96 & 121.13 & 130.85 & 223.95 \\
\hline own account & 14.38 & ----- & 116.25 & ---- & 185.77 & ---- & 233.69 & 154.96 & 121.13 & ---- & 82.76 \\
\hline customer & ---- & 317.1 & 588.68 & 354.22 & ---- & 57.61 & 196.78 & ---- & ---- & 130.85 & 141.2 \\
\hline \multicolumn{12}{|c|}{ Japanese Yen } \\
\hline Trader days & 2 & 42 & 10 & 25 & 262 & 8 & 45 & 185 & 10 & 10 & 19 \\
\hline Transactions & 31 & 6,550 & 760 & 2,196 & 17,070 & 31 & 3,163 & 8,278 & 110 & 515 & 1,112 \\
\hline Volume & 59 & 69,635 & 7,303 & 28,661 & 73,002 & 254 & 10,734 & 32,873 & 200 & 2,936 & 6,014 \\
\hline $\begin{array}{l}\text { Average daily } \\
\text { trades: }\end{array}$ & 15.5 & 155.95 & 76 & 87.84 & 65.15 & 3.88 & 70.29 & 44.75 & 11 & 51.5 & 58.53 \\
\hline own account & 15.5 & ---- & 8.6 & ---- & 65.15 & ----- & 62.76 & 44.75 & 11 & ---- & 12.95 \\
\hline customer & ----- & 155.95 & 67.4 & 87.84 & ---- & 3.88 & 7.53 & ---- & ---- & 51.5 & 45.58 \\
\hline $\begin{array}{l}\text { Average daily } \\
\text { volume: }\end{array}$ & 29.5 & $1,657.98$ & 730.3 & $1,146.44$ & 278.63 & 31.75 & 238.53 & 177.69 & 20 & 293.6 & 316.53 \\
\hline own account & 29.5 & ---- & 35.5 & ---- & 278.63 & ----- & 224.49 & 177.69 & 20 & ----- & 41.11 \\
\hline customer & ---- & $1,657.98$ & 694.8 & $1,146.44$ & ---- & 31.75 & 14.04 & ---- & - & 293.6 & 275.42 \\
\hline
\end{tabular}

Dual-brokers (dual-locals) are floor traders who were classified as dual traders before the restrictions but switched to trading only for their customers' (own) accounts following the restrictions. Dual-quitters are floor traders who were classified as dual traders before the restrictions but quit trading in the affected contract month afterwards. The sample periods are May 1 to July 31, 1987 for the S\&P 500 and April 1 to June 28, 1991 for the Japanese Yen. 
Table 6

Activity of Continuing Dual Traders

S\&P 500 and Japanese Yen Futures

\begin{tabular}{|c|c|c|c|c|c|c|}
\hline \multirow[b]{3}{*}{ Trader Day Type } & \multicolumn{6}{|c|}{ Dual-duals } \\
\hline & \multicolumn{3}{|c|}{ Before } & \multicolumn{3}{|c|}{ After } \\
\hline & Local & Broker & Dual & Local & Broker & Dual \\
\hline \multicolumn{7}{|c|}{ S\&P 500} \\
\hline Trader days & 513 & 465 & 2,530 & 865 & 1,531 & 947 \\
\hline Transactions & 26,070 & 29,151 & 390,577 & 56,017 & 203,095 & 102,146 \\
\hline Trading volume & 77,709 & 151,184 & $1,353,170$ & 203,075 & 672,679 & 308,554 \\
\hline Average daily trades: & 50.82 & 62.69 & 154.38 & 64.76 & 132.66 & 107.86 \\
\hline own account & 50.82 & ----- & 42.88 & 64.76 & ----- & 40.13 \\
\hline customer & ----- & 62.69 & 111.5 & ----- & 132.66 & 67.74 \\
\hline Average daily volume: & 151.48 & 325.13 & 534.85 & 234.77 & 439.37 & 325.82 \\
\hline own account & 151.48 & ----- & 168.77 & 234.77 & ----- & 119.74 \\
\hline customer & ------ & 325.13 & 366.08 & ----- & 439.37 & 206.08 \\
\hline \multicolumn{7}{|c|}{ Japanese Yen } \\
\hline Trader days & 89 & 323 & 487 & 106 & 480 & 129 \\
\hline Transactions & 4,799 & 38,072 & 54,250 & 4,288 & 34,482 & 6,940 \\
\hline Trading volume & 12,626 & 165,120 & 285,437 & 12,602 & 209,831 & 33,579 \\
\hline Average daily trades: & 53.92 & 117.87 & 111.4 & 40.45 & 71.84 & 53.8 \\
\hline own account & 53.92 & ----- & 23.38 & 40.45 & ----- & 11.8 \\
\hline customer & ----- & 117.87 & 88.01 & ----- & 71.84 & 42 \\
\hline Average daily volume: & 141.87 & 511.21 & 586.11 & 118.89 & 437.15 & 260.3 \\
\hline own account & 141.87 & ----- & 73.58 & 118.89 & ----- & 43.84 \\
\hline customer & ----- & 511.21 & 512.53 & ----- & 437.15 & 216.46 \\
\hline
\end{tabular}

Dual-duals are floor traders who were classified as dual traders both before and after dual trading restrictions. The sample periods are May 1 to July 31, 1987 for the S\&P 500 and April 1 to June 28, 1991 for the Japanese Yen. 
Table 7

Dual Trader Personal Trading Quantities on their Exclusive Local Days

S\&P 500 and Japanese Yen Futures

\begin{tabular}{|c|c|c|c|c|}
\hline & Dual-duals & Dual-brokers & Dual-locals & Dual-quitters \\
\hline \multicolumn{5}{|c|}{ S\&P 500} \\
\hline Mean Quantity & 151.48 & 14.83 & 185.77 & 121.13 \\
\hline $\begin{array}{l}\text { Standard } \\
\text { deviation }\end{array}$ & 162.7 & 12.25 & 213.45 & 135.55 \\
\hline Median & 137 & 13 & 216.9 & 115 \\
\hline $\begin{array}{l}\text { Wilcoxon } Z \\
\text { Prob }>Z\end{array}$ & & $\begin{array}{c}-0.9771 \\
(0.4984)\end{array}$ & $\begin{array}{c}2.018^{\star} \\
(0.0435)\end{array}$ & $\begin{array}{l}-2.7091^{\star} \\
(0.0068)\end{array}$ \\
\hline$N$ & 513 & 24 & 892 & 146 \\
\hline \multicolumn{5}{|c|}{ Japanese Yen } \\
\hline Mean Quantity & 141.87 & 29.5 & 278.63 & 20 \\
\hline $\begin{array}{l}\text { Standard } \\
\text { deviation }\end{array}$ & 135.2 & 10.6 & 282.45 & 16.12 \\
\hline Median & 126 & 29.5 & 260 & 17 \\
\hline $\begin{array}{l}\text { Wilcoxon } Z \\
\text { Prob }>Z\end{array}$ & & $\begin{array}{c}-0.6482 \\
(0.7277)\end{array}$ & $\begin{array}{l}1.8693^{\star} \\
(0.0825)\end{array}$ & $\begin{array}{l}-1.1376 \\
(0.2556)\end{array}$ \\
\hline$N$ & 89 & 2 & 262 & 10 \\
\hline
\end{tabular}

Dual traders' personal trading quantities on their exclusive local days are compared for the pre-rule period. Dual-duals are floor traders who dual traded both before and after dual trading restrictions during our sample period. Dual-brokers (dual-locals) are floor traders who dual traded before the restrictions but switched to trading only for their customers' (own) accounts following the restrictions. Dual-quitters are floor traders who dual traded before the restrictions but quit trading in the affected contract month afterwards. The $Z$-statistic tests for differences in the distribution of quantities between dual-duals and the other groups of dual traders. Significant differences are starred. $N$ is the number of observations. The sample periods are May 1 to June 20, 1987 for the S\&P 500 and April 1 to May 19, 1991 for the Japanese Yen. 
Table 8

Dual Trader Personal Trading Revenues Per Contract on their Exclusive Local Days

S\&P 500 and Japanese Yen Futures

\begin{tabular}{|c|c|c|c|c|}
\hline & Dual-duals & Dual-brokers & Dual-locals & Dual-quitters \\
\hline \multicolumn{5}{|c|}{ S\&P 500 } \\
\hline Mean Profits & 43 & 19.5 & 259.5 & 158 \\
\hline Standard deviation & 486.5 & 477.5 & 1121.5 & 680 \\
\hline Median & 17.5 & 17 & 50 & 38 \\
\hline $\begin{array}{l}\text { Wilcoxon } Z \\
(\text { Prob }>Z)\end{array}$ & & $\begin{array}{r}-017173 \\
(0.8636) \\
\end{array}$ & $\begin{array}{l}2.4753^{\star} \\
(0.0350) \\
\end{array}$ & $\begin{array}{l}2.68627^{\star} \\
(0.0072)\end{array}$ \\
\hline$N$ & 513 & 24 & 892 & 146 \\
\hline \multicolumn{5}{|c|}{ Japanese Yen } \\
\hline Mean Profits & 4.13 & 27.5 & -0.0125 & 7.5 \\
\hline Standard deviation & 161.75 & 31.88 & 106.38 & 45.88 \\
\hline Median & 5.63 & 27.5 & 7.63 & 5 \\
\hline $\begin{array}{l}\text { Wilcoxon } Z \\
\text { Prob }>Z\end{array}$ & & $\begin{array}{l}0.8798 \\
(0.379) \\
\end{array}$ & $\begin{array}{r}0.74814 \\
(0.4544) \\
\end{array}$ & $\begin{array}{c}0 \\
(0.9999) \\
\end{array}$ \\
\hline$N$ & 89 & 2 & 262 & 10 \\
\hline
\end{tabular}

Revenues per contract (in dollars) are calculated for dual traders' personal trades on their exclusive local days for the pre-rule period. Dual-duals are floor traders who dual traded both before and after dual trading restrictions during our sample period. Dual-brokers (duallocals) are floor traders who dual traded before the restrictions but switched to trading only for their customers' (own) accounts following the restrictions. Dual-quitters are floor traders who dual traded before the restrictions but quit trading in the affected contract month afterwards. The Z-statistic tests for differences in the distribution of revenues between dual-duals and the other groups of dual traders. Significant differences are starred. $N$ is the number of observations. The sample periods are May 1 to June 20, 1987 for the S\&P 500 and April 1 to May 19, 1991 for the Japanese Yen. 
Table 9

Customer Trading Costs on Broker Days Before and After Restrictions

For Different Groups of Dual Traders

\begin{tabular}{lllll}
\hline & Dual-duals & Dual-brokers & Non-brokers & All brokers \\
\hline & Before & Before & Before & After \\
\hline Mean costs & & S\&P 500 & \\
Standard deviation & 293.05 & 56.48 & 35.27 & 62.09 \\
Median & 41.24 & 315.21 & 334.41 & 341.6 \\
Wilcoxon $Z$ & 1.4963 & 36.43 & 38.64 & 59.49 \\
(Prob>Z) & $(0.16)$ & 1.6254 & $1.7953^{\star}$ & \\
\hline$N$ & 439 & $(0.1042)$ & $(0.07)$ & \\
\hline & & 102 & 44 & 2661 \\
\hline Mean costs & Japanese Yen & & \\
Standard deviation & 172.88 & 8.75 & 51.5 & 10.75 \\
Median & 34.13 & 156.25 & 506.25 & 308.8 \\
Wilcoxon $Z$ & 0.7635 & 19.13 & 10.38 & 21.88 \\
(Prob> $Z$ ) & $(0.45)$ & 0.6742 & 1.3232 & \\
\hline$N$ & 308 & $(0.5)$ & $18.186)$ & 785 \\
\hline
\end{tabular}

Customer trading costs (in dollars) are calculated for broker days of dual traders for the pre-rule period (before) and for broker days of all brokers (dual traders and pure brokers) in the post-rule period (after). Dual-duals are floor traders who dual traded both before and after dual trading restrictions during our sample period. Dual-brokers are floor traders who dual traded before the restrictions but traded only for their customers' accounts following the restrictions. Non-brokers are floor traders who dual traded before the restrictions but quit brokerage in the affected contract month afterwards. The Z-statistic measures differences in the distribution of customer trading costs between the three groups in the pre-rule period and all brokers in the post-rule period. $P$-values are in parentheses. Significant differences are starred. $N$ is the number of observations. The sample periods are May 1 to June 20, 1987 for the S\&P 500 and April 1 to May 19, 1991 for the Japanese Yen.

1. All-brokers include both dual traders and pure brokers in the post-rule period. 


\section{Table 8}

\section{Dual Trader Personal Trading Quantities on their Exclusive Local Days: Brokers and Non-brokers}

\section{S\&P 500 and Japanese Yen Futures}

Dual traders' personal trading quantities on their exclusive local days are compared for the pre-rule period. After-brokers include both dual-duals (i.e., floor traders who dual traded both before and after dual trading restrictions during our sample period) and dual-brokers (i.e., floor traders who dual traded before the restrictions but switched to trading only for their customers' accounts following restrictions). After-locals are dual-locals (i.e., floor traders who dual traded before the restrictions but switched to trading only for their own accounts following restrictions). After-quitters are dual-quitters (i.e., floor traders who dual traded before the restrictions but quit trading in the affected contract month afterwards). The $\mathrm{z}$ statistic tests for differences in median quantities between after-brokers and the other two groups of dual traders. The sample periods are May 1 to June 20, 1987 for the S\&P 500 and April 1 to May 19, 1991 for the Japanese Yen.

\begin{tabular}{|c|c|c|c|}
\hline & After-brokers & After-locals & After-quitters \\
\hline \multicolumn{4}{|c|}{ S\&P 500} \\
\hline Mean Quantity & 145.37 & 185.77 & 121.13 \\
\hline Standard deviation & 160.3 & 213.45 & 135.55 \\
\hline Minimum & 1 & 3 & 2 \\
\hline 1st Quartile & 20 & 127 & 55 \\
\hline Median & 124 & 216.9 & 115 \\
\hline 3rd Quartile & 157 & 274 & 192 \\
\hline Maximum & 483 & 468 & 313 \\
\hline Difference in medians & & $92.9^{\star}$ & $-9^{\star}$ \\
\hline Wilcoxon z-statistic & & $\begin{array}{l}2.0054^{\star} \\
(0.0466) \\
\end{array}$ & $\begin{array}{l}-2.5156^{\star} \\
(0.0095) \\
\end{array}$ \\
\hline & $\mathrm{N}=\mathbf{5 3 7}$ & $\mathrm{N}=892$ & $\mathrm{~N}=146$ \\
\hline \multicolumn{4}{|c|}{ Japanese Yen } \\
\hline Mean Quantity & 139.34 & 278.63 & 20 \\
\hline Standard deviation & 134.1 & 282.45 & 16.12 \\
\hline Minimum & 1 & 3 & 1 \\
\hline 1st Quartile & 19 & 145 & 6 \\
\hline Median & 124 & 260 & 17 \\
\hline 3rd Quartile & 219 & 587 & 45 \\
\hline Maximum & 426 & 587 & 45 \\
\hline Difference in medians & & 136 & -107 \\
\hline Wilcoxon z-statistic & & $\begin{array}{c}1.869^{\star} \\
(0.0822)\end{array}$ & $\begin{array}{l}-1.1376 \\
(0.2556)\end{array}$ \\
\hline
\end{tabular}




\begin{tabular}{llc}
\hline $\mathrm{N}=91$ & $\mathrm{~N}=262$ & $\mathrm{~N}=10$ \\
\hline
\end{tabular}

Table 9

Dual Trader Personal Trading Revenues Per Contract on their Exclusive Local Days:
Brokers and Non-brokers
S\&P 500 and Japanese Yen Futures

Revenues per contract (in dollars) are calculated for dual traders' personal trades on their exclusive local days for the pre-rule period. After-brokers include both dual-duals (i.e., floor traders who dual traded both before and after dual trading restrictions during our sample period) and dual-brokers (i.e., floor traders who dual traded before the restrictions but switched to trading only for their customers' accounts following restrictions). After-locals are dual-locals (i.e., floor traders who dual traded before the restrictions but switched to trading only for their own accounts following restrictions). After-quitters are dual-quitters (i.e., floor traders who dual traded before the restrictions but quit trading in the affected contract month afterwards). The z-statistic tests for differences in median revenues between after-brokers and the other two groups of dual traders. The sample periods are May 1 to June 20, 1987 for the S\&P 500 and April 1 to May 19, 1991 for the Japanese Yen.

\begin{tabular}{|c|c|c|c|}
\hline & After-brokers & After-locals & After-quitters \\
\hline \multicolumn{4}{|c|}{ S\&P 500} \\
\hline Mean Profits & 41.5 & 259.5 & 158 \\
\hline Standard deviation & 486 & 1121.5 & 680 \\
\hline Minimum & -3565 & -1075 & -2624.5 \\
\hline 1st Quartile & -9.5 & -217.5 & -23 \\
\hline Median & 17 & 50 & 38 \\
\hline 3rd Quartile & 55 & 84.5 & 175 \\
\hline Maximum & 3650 & 3308.5 & 3712.5 \\
\hline Difference in medians & & $33^{\star}$ & $21^{\star}$ \\
\hline Wilcoxon z-statistic & & $\begin{array}{l}2.4755^{\star} \\
(0.0352)\end{array}$ & $\begin{array}{r}2.684^{\star} \\
(0.0070)\end{array}$ \\
\hline & $\mathbf{N}=\mathbf{5 3 7}$ & $\mathrm{N}=892$ & $N=146$ \\
\hline \multicolumn{4}{|c|}{ Japanese Yen } \\
\hline Mean Profits & 46.38 & -0.125 & 75 \\
\hline Standard deviation & 1615 & 1063.75 & 458.75 \\
\hline Minimum & 7412.5 & -5487.5 & -475 \\
\hline 1st Quartile & 100 & -137.5 & -300 \\
\hline Median & 56.25 & 76.25 & 50 \\
\hline 3rd Quartile & 193.75 & 226.25 & 625 \\
\hline Maximum & 10500 & 4781.25 & 708.75 \\
\hline Difference in medians & & 20 & -6.25 \\
\hline
\end{tabular}


Table 10

\section{Dual Trader Daily Personal Trading Revenues on their Exclusive Local Days: Brokers and Non-brokers S\&P 500 and Japanese Yen Futures}

Average daily revenues (in dollars) are calculated for dual traders' personal trades on their exclusive local days for the prerule period. After-brokers include both dual-duals (i.e., floor traders who dual traded both before and after dual trading restrictions during our sample period) and dual-brokers (i.e., floor traders who dual traded before the restrictions but switched to trading only for their customers' accounts following restrictions). After-locals are dual-locals (i.e., floor traders who dual traded before the restrictions but switched to trading only for their own accounts following restrictions). After-quitters are dual-quitters (i.e., floor traders who dual traded before the restrictions but quit trading in the affected contract month afterwards). The z-statistic tests for differences in median revenues between after-brokers and the other two groups of dual traders. The sample periods are May 1 to June 20, 1987 for the S\&P 500 and April 1 to May 19, 1991 for the Japanese Yen.

\begin{tabular}{|c|c|c|c|}
\hline & After-brokers & After-locals & After-quitters \\
\hline \multicolumn{4}{|c|}{ S\&P 500 } \\
\hline Mean Profits & $2,450.00$ & $13,000.00$ & $7,900.00$ \\
\hline Standard deviation & $241,900.00$ & $560,750.00$ & $340,000.00$ \\
\hline Minimum & $(1,782,500.00)$ & $(1,620,000.00)$ & $(\mathbf{1 , 3 1 2 , 2 5 0 . 0 0 )}$ \\
\hline 1st Quartile & $(4,550.00)$ & $(10,900.00)$ & $(11,500.00)$ \\
\hline Median & $8,500.00$ & $25,000.00$ & $19,000.00$ \\
\hline 3rd Quartile & $23,750.00$ & $42,250.00$ & $87,500.00$ \\
\hline Maximum & $1,825,000.00$ & $1,654,250.00$ & $1,856,250.00$ \\
\hline Difference in medians & & $16,500.00^{\star}$ & $10,500.00$ \\
\hline Wilcoxon z-statistic & & $\begin{array}{l}1.6705^{\star} \\
(0.1056) \\
\end{array}$ & $\begin{array}{r}0.684 \\
(0.4271) \\
\end{array}$ \\
\hline & $\mathrm{N}=\mathbf{5 3 7}$ & $\mathrm{N}=892$ & $N=146$ \\
\hline \multicolumn{4}{|c|}{ Japanese Yen } \\
\hline Mean Profits & $5,800.00$ & $7,812.50$ & $9,375.00$ \\
\hline Standard deviation & $202,925.00$ & $132,975.00$ & $57,350.00$ \\
\hline Minimum & $(3,706,250.00)$ & $(685,937.50)$ & $(59,375.00)$ \\
\hline 1st Quartile & $6,250.00$ & $(68,750.00)$ & $(37,500.00)$ \\
\hline Median & $7,037.50$ & $\mathbf{9 , 5 3 7 . 5 0}$ & $6,250.00$ \\
\hline 3rd Quartile & $24,387.50$ & $28,287.50$ & $78,125.00$ \\
\hline Maximum & $1,312,500.00$ & $597,662.50$ & $88,600.00$ \\
\hline Difference in medians & & $2,500.00$ & $(\mathbf{7 8 7 . 5 0})$ \\
\hline Wilcoxon z-statistic & & $\begin{array}{r}1.0545 \\
(0.1462) \\
\end{array}$ & $\begin{array}{c}-\mathbf{- 0 . 8 5 9} \\
(\mathbf{0 . 6 2 2 7}) \\
\end{array}$ \\
\hline & $\mathrm{N}=91$ & $\mathrm{~N}=262$ & $\mathrm{~N}=\mathbf{1 0}$ \\
\hline
\end{tabular}


Table 9

Dual Trader Personal Trading Revenues Per Contract on their Exclusive Local Days: Brokers and Non-brokers

\section{S\&P 500 and Japanese Yen Futures}

Revenues per contract (in dollars) are calculated for dual traders' personal trades on their exclusive local days for the pre-rule period. After-brokers include both dual-duals (i.e., floor traders who dual traded both before and after dual trading restrictions during our sample period) and dual-brokers (i.e., floor traders who dual traded before the restrictions but switched to trading only for their customers' accounts following restrictions). After-locals are dual-locals (i.e., floor traders who dual traded before the restrictions but switched to trading only for their own accounts following restrictions). After-quitters are dual-quitters (i.e., floor traders who dual traded before the restrictions but quit trading in the affected contract month afterwards). The z-statistic tests for differences in median revenues between after-brokers and the other two groups of dual traders. The sample periods are May 1 to June 20, 1987 for the S\&P 500 and April 1 to May 19, 1991 for the Japanese Yen. 


\section{Table 5 \\ Differences in Dual Traders' Execution Skills in the S\&P 500 and Japanese Yen Pits}

Trading costs are calculated for dual traders' customers on the dual traders' broker days for the pre-rule period. Continuing dual traders are floor traders who dual traded both before and after dual trading restrictions during our sample period. D ual-brokers (dual-locals) are floor traders who dual traded before the restrictions but switched to trading only for their customers'(own) accounts following the restrictions. D ual-quitters are floor traders who dual traded before the restrictions but quit trading in the affected contract month afterwards. The F-statistic measures differences in customer trading costs between continuing and other groups of dual traders. For the Japanese Y en, costs have been multiplied by 10,000. P-values are in parentheses. $\mathrm{N}$ is the number of observations. The sample periods are May 1 to June 20, 1987 for the S\&P 500 and April 1 to May 19, 1991 for the Japanese Yen.

\begin{tabular}{|c|c|c|c|c|}
\hline & Continuing dual traders & Dual-brokers & Dual-locals & Dual-quitters \\
\hline \multicolumn{5}{|c|}{ S\&P 500} \\
\hline Mean costs & 21.62 & -8.81 & 0.31 & 2.69 \\
\hline Standard deviation & 22.53 & 34.38 & 35.89 & 50.3 \\
\hline Standard error & 3.81 & 5.81 & 6.61 & 9.87 \\
\hline \multirow[t]{2}{*}{$\begin{array}{l}\text { Wilcoxon Z S tatistic } \\
(\text { Prob }>\text { Z) }\end{array}$} & & $\begin{array}{c}-2.31 \\
(0.0076) \\
\end{array}$ & $\begin{array}{c}-1.41 \\
(0.2392) \\
\end{array}$ & $\begin{array}{c}-0.89 \\
(0.1261) \\
\end{array}$ \\
\hline & $\mathrm{N}=35$ & $\mathrm{~N}=35$ & $\mathrm{~N}=35$ & $\mathrm{~N}=26$ \\
\hline \multicolumn{5}{|c|}{ Japanese Y en } \\
\hline Mean costs & 3.09 & -2.46 & -4.35 & -3.63 \\
\hline Standard deviation & 4.44 & 6.00 & 16.45 & 16.05 \\
\hline Standard error & 0.75 & 0.21 & 4.75 & 5.08 \\
\hline \multirow[t]{2}{*}{$\begin{array}{l}\text { Wilcoxon Z-statistic } \\
(\text { Prob }>Z)\end{array}$} & & $\begin{array}{l}-0.42 \\
(0.55) \\
\end{array}$ & $\begin{array}{c}-0.58 \\
(0.3904) \\
\end{array}$ & $\begin{array}{c}1.27 \\
(0.1369) \\
\end{array}$ \\
\hline & $\mathrm{N}=35$ & $\mathrm{~N}=12$ & $\mathrm{~N}=8$ & $\mathrm{~N}=10$ \\
\hline
\end{tabular}




\section{Table 9}

\section{Adverse Selection Costs Faced by Marketmakers Executing for Dual Trading}

\section{Customers in the S\&P 500 Pit}

Adverse selection costs faced by marketmakers for the pre-rule period are estimated using SUR from the following regression system:

(1) $C_{t}=a_{0}+a_{1}\left(Q_{t}-Q_{t-1}\right)+a_{2}\left(V_{t} Q_{t}\right)+a_{3} M_{t}+e_{t}$

(2) $C_{t, j}=b_{0}+b_{1}\left(Q_{t, j}-Q_{t-1, j}\right)+b_{2}\left(V_{t, j} Q_{t, j}\right)+b_{3} M_{t}+e_{t, j}$ for $j=1,2,3$

where (1) is for continuing dual traders. In (2), the index $\mathrm{j}=1$ for dual-locals, 2 for dual-brokers, and 3 for dual-quitters. For group $\mathrm{j}, C_{t}, j$ is the price difference between intervals $t$ and $t-1$, and in interval $t$, $Q_{t, j}$ is a buy/ sell indicator, $V_{t, j}$ is the net (unsigned) customer trading volume and $M_{t}$ is the number of floor brokers trading for their own accounts. D ual-brokers (dual-locals) are floor traders who dual traded before restrictions but switched to trading only for customers'(own) accounts following restrictions. D ual-quitters are floor traders who dual traded before restrictions but quit trading in the affected contract month afterwards. The chi-square statistic tests for $\mathrm{a}_{2}=\mathrm{b}_{2}$. T-statistics are shown in parentheses. Nis the number of observations. The sample periods are May 1 to June 20,1987 for the $S \& P 500$.

\begin{tabular}{|c|c|c|c|c|c|c|c|}
\hline \multicolumn{4}{|c|}{ Continuing dual traders } & \multicolumn{4}{|c|}{ Discontinuing dual traders } \\
\hline$a_{0}$ & $a_{1}$ & $a_{2}$ & $a_{3}$ & $b_{0}$ & $b_{1}$ & $b_{2}$ & $b_{3}$ \\
\hline $\begin{array}{l}11.96 \\
(1.03) \\
\end{array}$ & $\begin{array}{l}5.21 \\
(1.449) \\
\end{array}$ & $\begin{array}{l}-0.083 \\
(-6.728) \\
\end{array}$ & $\begin{array}{c}-0.065 \\
(-1.01) \\
\end{array}$ & $\begin{array}{l}12.42 \\
(1.048) \\
\end{array}$ & $\begin{array}{l}0.879 \\
(0.256) \\
\end{array}$ & $\begin{array}{l}-0.047 \\
(-1.14) \\
\end{array}$ & $\begin{array}{l}-0.06 \\
(-0.87) \\
\end{array}$ \\
\hline $\mathrm{N}=$ & $\mathrm{H}_{0}: \mathrm{a}_{2}=\mathrm{b}_{2}$ & Chi-sque & $=8$ & Prob $>c$ & & & \\
\hline $\begin{array}{l}8.704 \\
(0.585) \\
\end{array}$ & $\begin{array}{l}2.899 \\
(0.868) \\
\end{array}$ & $\begin{array}{c}-0.076 \\
(-6.65) \\
\end{array}$ & $\begin{array}{l}-0.033 \\
(-0.628)\end{array}$ & $\begin{array}{l}1.842 \\
(0.214)\end{array}$ & $\begin{array}{l}-0.534 \\
(-0.167)\end{array}$ & $\begin{array}{l}-0.045 \\
(-1.20)\end{array}$ & $\begin{array}{l}0.005 \\
(0.094)\end{array}$ \\
\hline $\mathrm{N}=$ & $\mathrm{H}_{0}: \mathrm{a}_{2}=\mathrm{b}_{2}$ & Chi-sque & & Prob $>c$ & & & \\
\hline $\begin{array}{l}-4.79 \\
(-0.21) \\
\end{array}$ & $\begin{array}{l}5.794 \\
(1.249) \\
\end{array}$ & $\begin{array}{l}-0.079 \\
(-5.42) \\
\end{array}$ & $\begin{array}{l}0.0198 \\
(0.172) \\
\end{array}$ & $\begin{array}{l}-13.2 \\
(-0.54) \\
\end{array}$ & $\begin{array}{l}2.816 \\
(0.6) \\
\end{array}$ & $\begin{array}{l}0.144 \\
(0.388) \\
\end{array}$ & $\begin{array}{l}0.078 \\
(0.615) \\
\end{array}$ \\
\hline $\mathrm{N}=$ & $\mathrm{H}_{0}: \mathrm{a}_{2}=\mathrm{b}_{2}$ & Chi-sque & & Prob $>c$ & & & \\
\hline
\end{tabular}

Table 9

Adverse Selection Costs Faced by Marketmakers Executing for Dual Trading Customers in the Japanese Yen Pit 
Adverse selection costs faced by marketmakers for the pre-rule period are estimated using SUR from the following regression system:

(1) $C_{t}=a_{0}+a_{1}\left(Q_{t}-Q_{t-1}\right)+a_{2}\left(V_{t} Q_{t}\right)+a_{3} M_{t}+e_{t}$

\section{(2) $C_{t, j}=b_{0}+b_{1}\left(Q_{t, j}-Q_{t-1, j}\right)+b_{2}\left(V_{t, j} Q_{t, j}\right)+b_{3} M_{t}+e_{t, j} f o r j=1,2,3$}

where (1) is for continuing dual traders. In (2), the index $\mathrm{j}=1$ for dual-locals, 2 for dual-brokers, and 3 for dual-quitters. For group $\mathrm{j}, C_{t}, j$ is the price difference between intervals $t$ and $t-1$, and in interval $t$, $Q_{t, j}$ is a buy/ sell indicator, $V_{t, j}$ is the net (unsigned) customer trading volume and $M_{t}$ is the number of floor brokers trading for their own accounts. D ual-brokers (dual-locals) are floor traders who dual traded before restrictions but switched to trading only for customers'(own) accounts following restrictions. D ual-quitters are floor traders who dual traded before restrictions but quit trading in the affected contract month afterwards. The chi-square statistic tests for $\mathrm{a}_{2}=\mathrm{b}_{2}$. T-statistics are shown in parentheses. Nis the number of observations. The sample periods are April 1 to May 19 , 1991 for the Japanese Yen.

\begin{tabular}{|c|c|c|c|c|c|c|c|}
\hline \multicolumn{4}{|c|}{ Continuing dual traders } & \multicolumn{4}{|c|}{ Discontinuing dual traders } \\
\hline$a_{0}$ & $a_{1}$ & $a_{2}$ & $a_{3}$ & $b_{0}$ & $b_{1}$ & $b_{2}$ & $b_{3}$ \\
\hline $\begin{array}{l}22.29 \\
(0.36) \\
\end{array}$ & $\begin{array}{l}32.05 \\
(3.00) \\
\end{array}$ & $\begin{array}{l}-0.203 \\
(-3.041) \\
\end{array}$ & $\begin{array}{l}-0.69 \\
(-0.34) \\
\end{array}$ & $\begin{array}{l}-33.42 \\
(-0.377) \\
\end{array}$ & $\begin{array}{l}-15.49 \\
(0.827) \\
\end{array}$ & $\begin{array}{l}0.162 \\
(0.075) \\
\end{array}$ & $\begin{array}{l}0.656 \\
(0.246) \\
\end{array}$ \\
\hline$N=$ & $\mathrm{H}_{0}: \mathrm{a}_{2}=\mathrm{b}_{2}$ & Chi-squa & & Prob $>$ ch & & & \\
\hline $\begin{array}{l}34.15 \\
(0.863) \\
\end{array}$ & $\begin{array}{l}0.064 \\
(0.064) \\
\end{array}$ & $\begin{array}{l}-0.15 \\
(-2.01) \\
\end{array}$ & $\begin{array}{l}-0.628 \\
(-0.514) \\
\end{array}$ & $\begin{array}{l}-4.56 \\
(-0.12) \\
\end{array}$ & $\begin{array}{l}-22.62 \\
(-2.27) \\
\end{array}$ & $\begin{array}{l}0.252 \\
(1.728) \\
\end{array}$ & $\begin{array}{l}0.725 \\
(0.636) \\
\end{array}$ \\
\hline $\mathrm{N}=$ & $\mathrm{H}_{0}: \mathrm{a}_{2}=\mathrm{b}_{2}$ & Chi-squa & & Prob $>$ ch & & & \\
\hline $\begin{array}{l}21.33 \\
(0.755) \\
\end{array}$ & $\begin{array}{l}0.227 \\
(0.035) \\
\end{array}$ & $\begin{array}{l}-0.105 \\
(-1.82) \\
\end{array}$ & $\begin{array}{l}-1.232 \\
(-1.41) \\
\end{array}$ & $\begin{array}{l}20.67 \\
(0.591) \\
\end{array}$ & $\begin{array}{l}0.635 \\
(0.08) \\
\end{array}$ & $\begin{array}{l}-0.547 \\
(-2.29)\end{array}$ & $\begin{array}{l}-0.51 \\
(0.481) \\
\end{array}$ \\
\hline $\mathrm{N}=$ & $\mathrm{H}_{0}: \mathrm{a}_{2}=\mathrm{b}_{2}$ & Chi-squa & & Prob $>$ ch & & & \\
\hline
\end{tabular}




\section{Dual Traders' Trading Skills Before and After Dual Trading Restrictions}

in the S\& P 500 Pit

Dual traders' personal trading revenues on their local days before and after dual trading restrictions are compared. The $\mathrm{z}$ statistc tests for the difference in median revenues before and after dual trading restrictions. P values are in parentheses. The mean, median and standard deviation of revenues for the Japanese Y en have been multiplied by 10,000. The sample periods are May 1 to July 31,1987 for the S\&P 500.

\begin{tabular}{lcc}
\hline & Local days of all dual traders & Local days of continuing dual traders \\
\hline \multicolumn{2}{c}{ Before } & After \\
\hline \multicolumn{2}{c}{ S\&P 500 } \\
\hline Mean & 0.06 & 0.051 \\
Standard deviation & 0.98 & 0.535 \\
Minimum & & \\
1st Quartile & -0.019 & -0.018 \\
Median & 0.034 & 0.031 \\
3rd Quartile & 0.09 & 0.081 \\
Maximum & 7.3 & 3.35 \\
Difference in medians & & -0.003 \\
Test z-statistic & & -0.893 \\
(prob. value) & & $(\quad)$ \\
\hline & $\mathrm{N}=1322$ & $\mathrm{~N}=830$ \\
\hline
\end{tabular}


Table 11

Dual Traders' Trading Skills Before and After Dual Trading Restrictions

in the Japanese Yen Pit

Dual traders' personal trading revenues on their local days before and after dual trading restrictions are compared. The $\mathrm{z}$ statistc tests for the difference in median revenues before and after dual trading restrictions.

$\mathrm{P}$ values are in parentheses. The mean, median and standard deviation of revenues for the Japanese Y en have been multiplied by 10,000. The sample periods are April 1 to June 28, 1991 for the Japanese Y en.

\begin{tabular}{|c|c|c|}
\hline \multicolumn{2}{|c|}{ Local days of all dual traders } & Local days of continuing dual traders \\
\hline \multicolumn{3}{|c|}{ Before } \\
\hline \multicolumn{3}{|c|}{ Japanese Y en Futures } \\
\hline Mean & -0.0073 & -10 \\
\hline Standard deviation & 9.73 & 6.15 \\
\hline \multicolumn{3}{|l|}{ Minimum } \\
\hline 1st Quartile & -1.2 & -1.1 \\
\hline Median & 0.53 & 0.26 \\
\hline 3rd Quartile & 1.7 & 1.18 \\
\hline Maximum & 84 & 10.59 \\
\hline Difference in media & & -0.27 \\
\hline \multirow[t]{2}{*}{$\begin{array}{l}\text { Test z-statistic } \\
\text { (prob. value) }\end{array}$} & & $\begin{array}{c}-1.482 \\
(\quad)\end{array}$ \\
\hline & $\mathrm{N}=367$ & $\mathrm{~N}=100$ \\
\hline
\end{tabular}


Table 12

Customer Trading Costs Before and After Dual Trading

Restrictions in the S\&P 500 and the Japanese Yen Pits

Changes in customer trading costs on account of dual trading restrictions are estimated from the following regression:

(1) $S_{t}=a_{0}+a 1 V_{t}+a_{2}$ VOLt $+a_{3} M_{t}+a_{4} D_{t}+e$

where, for day t, $S_{t}$ is customers' trading costs, $V_{t}$, is customer trading volume, $V O L_{t}$ is the standard deviation of buy prices for customer trades, $M_{t}$ is the number of floor brokers trading for their own accounts, and $D_{t}=1$ in the pre-rule period and 0 otherwise. For the Japanese Yen, the coefficients have been multiplied by 100,000 . T-statistics are shown in parentheses. Nis the number of observations. The sample periods are May 1 to June 20, 1987 for the S\&P 500 and April 1 to May 19, 1991 for the Japanese Yen.

\begin{tabular}{|c|c|c|c|c|}
\hline \multicolumn{5}{|c|}{ S\&P 500 Futures } \\
\hline$a_{0}$ & $a_{1}$ & $a_{2}$ & $a_{3}$ & $b_{0}$ \\
\hline $\begin{array}{l}20.21 \\
(3.44) \\
\end{array}$ & $\begin{array}{r}-0.0005 \\
(-2.007) \\
\end{array}$ & $\begin{array}{l}0.168 \\
(4.128) \\
\end{array}$ & $\begin{array}{l}-0.03 \\
(-0.81) \\
\end{array}$ & $\begin{array}{l}4.74 \\
(1.304) \\
\end{array}$ \\
\hline $\mathrm{N}=63$ & $F=11.083$ & Prob $>F$ & & \\
\hline \multicolumn{5}{|c|}{ Japanese Yen Futures } \\
\hline $\begin{array}{l}-1.62 \\
(1.334) \\
\end{array}$ & $\begin{array}{c}-0.0001 \\
(0.332) \\
\end{array}$ & $\begin{array}{l}1129.3 \\
(2.47) \\
\end{array}$ & $\begin{array}{l}0.04 \\
(1.25) \\
\end{array}$ & $\begin{array}{l}0.07 \\
(0.079) \\
\end{array}$ \\
\hline $\mathrm{N}=63$ & $\mathrm{~F}=5.036$ & Prob $>F$ & & \\
\hline
\end{tabular}


Table 13

The Effect of Dual Trading Restrictions on Marketmakers' Personal Trading Revenues

in the S\& P 500 Pit

Before (after) refers to floor traders' personal trading revenues per contract before (after) dual trading restrictions. The z statistc tests for the difference in median revenues before and after dual trading restrictions. $\mathrm{P}$ values are in parentheses. The sample periods are May 1 to July 31, 1987 for the S\&P 500.

\begin{tabular}{lcc|}
\hline & Before & After \\
\hline & S\&P 500 & \\
\hline Mean & 0.048 & 0.029 \\
Standard deviation & 0.775 & 0.517 \\
Minimum & -7.342 & -6.16 \\
1st Quartile & -0.023 & -0.012 \\
Median & 0.038 & 0.029 \\
3rd Quartile & 0.113 & 0.073 \\
Maximum & 7.791 & 16.35 \\
Difference in medians & ---- & -0.009 \\
Test z-statistic & ---- & -8.466 \\
(prob. value) & & $(0.0001)$ \\
\hline & $\mathrm{N}=11379$ & $\mathrm{~N}=9567$ \\
\hline
\end{tabular}


Table 14

The Effect of Dual Trading Restrictions on Marketmakers' Personal Trading Revenues in the Japanese Yen Pit

Before (after) refers to floor traders' personal trading revenues per contract before (after) dual trading restrictions. The $\mathrm{z}$ statistc tests for the difference in median revenues before and after dual trading restrictions. $\mathrm{P}$ values are in parentheses. The mean, median and standard deviation of revenues for the Japanese Y en have been multiplied by 10,000. The sample periods are April 1 to June 28, 1991 for the Japanese Y en

futures.

\begin{tabular}{lcc|}
\hline & Before & After \\
\hline & Japanese Yen & \\
\hline Mean & -0.6 & 0.12 \\
Standard deviation & 11.38 & 8.04 \\
Minimum & -114.4 & -80.6 \\
1st Quartile & -1.2 & -0.7 \\
Median & 0.55 & 0.5 \\
3rd Quartile & 1.85 & 1.47 \\
Maximum & 104.22 & 76.64 \\
Difference in medians & ----- & -0.38 \\
Test z-statistic & ---- & -0.3411 \\
& & $(0.7330)$ \\
\hline
\end{tabular}


Table 2

Activity of Floor Traders Before and After Dual Trading Restrictions in the S\&P 500 and Japanese Yen Futures Pits at the Chicago Mercantile Exchange

O wn account (customers) refers to floor traders who traded exclusively for their own (customers) account during the sample period. Both refers to floor traders who traded both for their own and their customers' accounts on the same day at least once during the sample period. There are 35 days before and 29 days after the dual trading restrictions for both contracts. The sample periods are May 1 to July 31 , 1987 for the S\&P 500 futures and April 1 to June 28, 1991 for the Japanese Y en futures.

\begin{tabular}{|c|c|c|c|c|c|c|c|c|}
\hline \multirow[b]{2}{*}{ Number of: } & \multicolumn{2}{|c|}{ Own account } & \multicolumn{2}{|c|}{ Customers } & \multicolumn{2}{|c|}{ Both } & \multicolumn{2}{|c|}{ All } \\
\hline & Before & After & Before & After & Before & After & Before & After \\
\hline & \multicolumn{8}{|c|}{ S\&P 500} \\
\hline Traders & 484 & 477 & 205 & 176 & 252 & 197 & 941 & 850 \\
\hline Trading days: & 7,339 & 7,426 & 912 & 1,025 & 5,416 & 4,268 & 13,667 & 12,719 \\
\hline own account only & 7,339 & 7,426 & & & 1,595 & 1,563 & 8,934 & 8,989 \\
\hline customer only & ---- & ---- & 912 & 1,025 & 648 & 1,668 & 1,560 & 2,693 \\
\hline dual & $-\cdots--$ & $-\cdots--$ & ---- & $-\cdots--$ & 3,173 & 1,037 & 3,173 & 1,037 \\
\hline Active days per trader: & 15.16 & 15.57 & 4.45 & 5.82 & 21.49 & 21.66 & 14.52 & 14.96 \\
\hline own account only & 15.16 & 15.57 & ----- & ---- & 6.33 & 7.93 & 9.49 & 10.58 \\
\hline customer only & ---- & $-\cdots--$ & 4.45 & 5.82 & 2.57 & 8.47 & 1.66 & 3.17 \\
\hline dual & $-\cdots--$ & ---- & ---- & $-\cdots--$ & 12.59 & 5.26 & 3.37 & 1.22 \\
\hline Active traders per day: & 209.69 & 256.07 & 26.06 & 35.34 & 154.74 & 147.17 & 390.49 & 438.59 \\
\hline own account only & 209.69 & 256.07 & $-\cdots--$ & $-\cdots--$ & 45.57 & 53.9 & 255.26 & 309.97 \\
\hline customer only & ---- & ---- & 26.06 & 35.34 & 18.51 & 57.52 & 44.57 & 92.86 \\
\hline \multirow[t]{2}{*}{ dual } & $-\cdots-\cdot$ & $-\cdots-$ & $----\cdot$ & $-\cdots-$ & 90.66 & 35.76 & 90.66 & 35.76 \\
\hline & \multicolumn{8}{|c|}{ Japanese Yen } \\
\hline Traders & 129 & 116 & 106 & 81 & 53 & 35 & 288 & 232 \\
\hline Trading days: & 1,867 & 1,310 & 588 & 403 & 1,320 & 767 & 3,775 & 2,480 \\
\hline own account only & 1,867 & 1,310 & ---- & $-\cdots--$ & 374 & 125 & 2,241 & 1,435 \\
\hline customer only & ---- & ---- & 588 & 403 & 383 & 507 & 971 & 910 \\
\hline dual & $-\cdots--$ & ---- & ----- & ---- & 563 & 135 & 563 & 135 \\
\hline Active days per trader: & 14.47 & 11.29 & 5.55 & 4.98 & 24.91 & 21.91 & 13.11 & 10.69 \\
\hline
\end{tabular}




\begin{tabular}{|c|c|c|c|c|c|c|c|c|}
\hline own account only & 14.47 & 11.29 & $-\cdots-$ & ---.- & 7.06 & 14.49 & 7.78 & 7.83 \\
\hline customer only & $\cdots-$ & $\cdots-$ & 5.55 & 4.98 & 7.23 & 3.57 & 3.37 & 2.28 \\
\hline dual & $\cdots-$ & $\cdots$ & $\cdots-$ & $\cdots$ & 10.62 & 3.86 & 1.95 & 0.58 \\
\hline own account only & 53.34 & 45.17 & ----- & ---- & 10.69 & 17.48 & 64.03 & 62.66 \\
\hline customer only & $-\cdots--$ & ---- & 16.8 & 13.9 & 10.94 & 4.31 & 27.74 & 18.21 \\
\hline dual & $-\cdots-$ & -.-- & -..-. & $\ldots$ & 16.09 & 4.66 & 16.09 & 4.66 \\
\hline
\end{tabular}

